Sharif University of Technology
Scientia Iranica
Transactions E: Industrial Engineering
http://scientiairanica.sharif.edu
IRAENTIA

\title{
A new decision approach to the sustainable transport investment selection based on the generalized entropy and knowledge measure under an interval-valued Pythagorean fuzzy environment
}

\author{
M. Aghamohagheghi ${ }^{a}$, S.M. Hashemi ${ }^{a, *}$, and R. Tavakkoli-Moghaddam ${ }^{\mathrm{b}}$ \\ a. Department of Mathematics and Computer Science, Amirkabir University of Technology, Tehran, Iran. \\ b. School of Industrial Engineering, College of Engineering, University of Tehran, Tehran, Iran. \\ Received 28 December 2017; received in revised form 26 May 2019; accepted 16 July 2019
}

\author{
KEYWORDS \\ Sustainable transport \\ appraisal; \\ Multi-criteria group \\ decision-making; \\ Entropy measure; \\ Knowledge measure; \\ Interval-valued \\ Pythagorean fuzzy \\ set.
}

\begin{abstract}
Finding the most suitable transport project is one of the most important tasks of transport planning. This task becomes much more complicated as sustainable criteria get involved. In this paper, a new method of multi-criteria group decision-making with an unknown attribute and expert weights is proposed to address the sustainable transport investment selection problem. To make the method more powerful in dealing with uncertain elements, an Interval-Valued Pythagorean Fuzzy (IVPF) set is used as a useful tool to handle uncertainty. First, a generalized entropy measure under an IVPF environment is introduced, which enables the method to determine the fuzziness of the attribute values, expressed by Interval-Valued Pythagorean Fuzzy Numbers (IVPFNs). To determine the fuzziness of IVPFNs with identical membership and non-membership degrees, a generalized knowledge measure of IVPFNs is also introduced. Based on this measure and considering the deviation among attribute assessments, a new optimization model is presented to obtain unknown attribute weights. In addition, based on the extension of the VIKOR method, a novel algorithm is introduced to determine the unknown expert weights. Finally, to prove the efficiency of the proposed methods, a real case study is considered.
\end{abstract}

(C) 2021 Sharif University of Technology. All rights reserved.

\section{Introduction}

Sustainable transportation is one of the most widely debated concepts in transportation. Sustainable transportation may be referred to a type of transportation that allows the movement of goods and people by modalities that are sustainable from social, eco-

*. Corresponding author.

E-mail address: hashemi@aut.ac.ir (S.M. Hashemi)

doi: $10.24200 /$ sci.2019.50131.1529 nomic, and environmental perspectives [1]. Awasthi et al. [2] classified the commonly used approaches to sustainability evaluation of transportation decisionmaking in eight categories. One of them is the MultiCriteria Decision-Making (MCDM). It is the preferred technique for solving problems with contradictory objectives and since three pillars of sustainability with their own measurement units can be involved in the process, it is reliable for sustainable transportation decisions [3]. Despite considering MCDM methods as the most common approaches of sustainable transportation assessment [4], when addressing uncertainty 
and impreciseness, they seem inadequate. In fact, all of the decisions that address transportation are mostly made under vague and uncertain situations. Since hard computing based MCDM methods are not able to effectively handle the ambiguities and uncertainties that transport decision-makers' face, sophisticated approaches are needed.

A variety of MCDM methods have been presented to handle a sustainable transportation evaluation problem under uncertainty [5-11]. Despite all the efforts to model the uncertainty of a sustainable transportation evaluation problem in MCDM methods, most of them were based on classical (FSs). In fact, there are few studies in the literature concerning sustainable transportation evaluation using an extension of classical Fuzzy Sets (FSs) [12-16]. No research has discussed the problem by utilizing the Interval-Valued Pythagorean Fuzzy Set (IVPFS). Therefore, there is a need to investigate more effective mathematical methods using these advanced uncertainty modeling tools to better handle sustainable transportation evaluation problems with high uncertainty.

A comparison between different types of FSs is conducted by reviewing their definitions and basic properties. Figure 1 illustrates the development logic of FSs. As shown in this figure, IVPFSs have an enormous ability and flexibility in expressing ambiguous data in real-world problems [17]. Consequently, this paper applies IVPFSs to solve the sustainable transport investment selection problem as an Multi-Criteria Group Decision Making (MCGDM) problem with unknown expert and attribute weights.
Generally, expert and attribute weighting methods can be mentioned as two important parts of the MCGDM process [18]. According to the information gathered about weighting approaches to MCGDM, they can be classified as objective and subjective approaches [19]. Most current related researches have investigated MCGDM in a fuzzy environment by integrating subjective weighting approaches [20-23]. Comparatively, there are still only a few studies on the development of objective weighting approaches in traditional MCGDM to fuzzy environments such as deviation functions [24] and fuzzy entropies [25,26]. On the other hand, the existing objective weighting approaches in fuzzy environments are only focused on the divergence of attribute assessments from the fuzziest number in a relevant environment while the deviation of attribute assessments or vice versa is neglected. Hence, it is necessary to investigate suitable methods to derive objective attribute weights in fuzzy environments that simultaneously consider the divergence of attribute evaluation from the fuzziest number and the deviation between attribute evaluations, particularly in the Interval-Valued Pythagorean Fuzzy (IVPF) environment. Therefore, firstly, the generalized entropy measure for IVPFSs is introduced so that one can consider the divergence of attribute assessments from the fuzziest number in the IVPF environment. In order to better distinguish the fuzziness of IntervalValued Pythagorean Fuzzy Numbers (IVPFNs) in cases, whose non-membership and membership degrees of IVPFNs are identical, a generalized knowledge measure of IVPFNs is proposed. Moreover, based on



Figure 1. Development logic of Fuzzy Sets (FSs). 
the generalized knowledge measure and the deviation between attribute assessments, a new optimization method is introduced. The proposed model utilizes all the available information of decision preferences to objectively compute the weights of unknown criteria as a very crucial component of MCGDM problems. The method is then developed to be applied to situations where the information about attribute weights is incomplete.

In the case of the MCGDM process, there is another strong need for revealing different influential saliencies of Decision-Makers (DMs) [27]; therefore, an expert weighting is also essential to MCGDM under IVPF uncertainty. Qi et al. [28] reviewed the methods that address the weights of DMs in MCGDM problems. Despite the fact that the existing methods have had a role in considering different influential saliencies of the DMs effectively, to the best of our knowledge, no study has investigated the methods that could calculate the weights of experts objectively through the extension of VIKOR method, as proposed by Opricovic [29].

In sum, the novelties of this study are explained as follows:

1. For the first time in the literature, an IVPFS as one of the most powerful tools in dealing with uncertainty is applied to increase the flexibility and ability of expressing and calculating the uncertainty in a transportation project evaluation problem;

2. A new MCGDM method with unknown attributes and expert weights is proposed under the IVPF environment to evaluate and rank a sustainable transport project;

3. A novel ranking index is defined to derive the ranks of the alternatives by applying a new weight of the strategy of the majority of criteria. The index is transparent and simple to use;

4. The concepts of entropy and knowledge measure are introduced under an IVPF environment to address the weights of unknown criteria. To utilize all the available information in decision preferences and create a more comprehensive weighting approach, a new optimization method is proposed that simultaneously considers the deviation between attribute assessments and knowledge measure. This optimization model is then extended so that it can be applied to decision makings with incomplete attribute weighting data;

5. A novel algorithm is proposed to objectively determine the weights of each DM in the IVPS environment based on the extension of the VIKOR method.

The rest of this paper is structured as follows. In Section 2, preliminary knowledge of IVPSs is described.
In Section 3, generalized measures for IVPFSs are introduced. An MCGDM problem under the IVPF environment is initially developed in Section 4 . In Subsection 4.1, a novel programming model is established to objectively obtain unknown and incomplete attribute weights. In Subsection 4.2, a new algorithm is proposed to objectively determine the weights of each expert in the IVPS environment based on the extension of the VIKOR method. A hybrid method composed of the aforementioned methods for MCGDM in IVPF environments is presented in Subsection 4.3. In Section 5, a method is applied to a real case study, and the results are presented and discussed. In the end, the conclusions of this paper are presented in Section 6.

\section{Preliminaries}

Definition 1. Let $D([0,1])$ be a set of all closed subintervals of $[0,1]$. Let $X$ denote a universe of discourse [30]. An IVPFS $\tilde{P}$ in $X$ is given by:

$$
\tilde{P}=\left\{x,\left[\tilde{\mu}_{\tilde{p}}^{l}(x), \tilde{\mu}_{\tilde{p}}^{u}(x)\right],\left[\tilde{\nu}_{\tilde{p}}^{l}(x), \tilde{\nu}_{\tilde{p}}^{u}(x)\right] \mid x \in X\right\},
$$

where $\left[\tilde{\mu}_{\tilde{p}}^{l}(x), \tilde{\mu}_{\tilde{p}}^{u}(x)\right] \subseteq[0,1],\left[\tilde{\nu}_{\tilde{P}}^{l}(x), \tilde{\nu}_{\tilde{P}}^{u}(x)\right] \subseteq[0,1]$ are interval values that denote the membership and non-membership degrees of element $x \in X$ in $\tilde{P}$, respectively. For every $x \in X, \tilde{\mu}_{\tilde{P}}^{l}(x), \tilde{\mu}_{\tilde{P}}^{u}(x), \tilde{\nu}_{\tilde{P}}^{l}(x)$, $\tilde{\nu}_{\tilde{P}}^{u}(x) \in[0,1]$, and $\left(\tilde{\mu}_{\tilde{P}}^{u}(x)\right)^{2}+\left(\tilde{\nu}_{\tilde{P}}^{u}(x)\right)^{2} \leq 1$.

The degree of indeterminacy of the membership function is denoted by:

$$
\begin{gathered}
\tilde{\pi}_{\tilde{P}}(x)=\left[\tilde{\pi}_{\tilde{P}}^{l}(x), \tilde{\pi}_{\tilde{P}}^{u}(x)\right]=\left[\sqrt{1-\left(\tilde{\mu}_{\tilde{P}}^{u}(x)\right)^{2}-\left(\tilde{\nu}_{\tilde{P}}^{u}(x)\right)^{2}},\right. \\
\left.\sqrt{1-\left(\tilde{\mu}_{\tilde{P}}^{l}(x)\right)^{2}-\left(\tilde{\nu}_{\tilde{P}}^{l}(x)\right)^{2}}\right]
\end{gathered}
$$

For convenience, Peng and Yang [30] named $\tilde{P}=$ $\left(\left[\tilde{\mu}_{\tilde{P}}^{l}, \tilde{\mu}_{\tilde{P}}^{u}\right],\left[\tilde{\nu}_{\tilde{P}}^{l}, \tilde{\nu}_{\tilde{P}}^{u}\right]\right)$ an IVPFN.

Definition 2. The improved accuracy function of any $\operatorname{IVPFN} \tilde{P}=\left(\left[\mu_{\tilde{P}}^{l}, \mu_{\tilde{P}}^{u}\right],\left[\nu_{\tilde{P}}^{l}, \nu_{\tilde{P}}^{u}\right]\right)$, based on hesitancy degree, is defined by Eq. (3) shown in Box I [31].

Definition 3. Let $\tilde{P}=\left(\left[\tilde{\mu}_{\tilde{P}}^{l}, \tilde{\mu}_{\tilde{P}}^{u}\right],\left[\tilde{\nu}_{\tilde{P}}^{l}, \tilde{\nu}_{\tilde{P}}^{u}\right]\right), \tilde{P}_{1}=$ $\left(\left[\tilde{\mu}_{\tilde{P}_{1}}^{l}, \tilde{\mu}_{\tilde{P}_{1}}^{u}\right],\left[\tilde{\nu}_{\tilde{P}_{1}}^{l}, \tilde{\nu}_{\tilde{P}_{1}}^{u}\right]\right)$, and $\tilde{P}_{2}=\left(\left[\tilde{\mu}_{\tilde{P}_{2}}^{l}, \tilde{\mu}_{\tilde{P}_{2}}^{u}\right],[\right.$ $\left.\left.\tilde{\nu}_{\tilde{P}_{2}}^{l}, \tilde{\nu}_{\tilde{P}_{2}}^{u}\right]\right)$ be IVPFNs and $\lambda>0$; then, their operations are defined by [30]:

$$
(\tilde{P})^{\complement}=\left(\left[\tilde{\nu}_{\tilde{P}}^{l}, \tilde{\nu}_{\tilde{P}}^{u}\right],\left[\tilde{\mu}_{\tilde{P}}^{l}, \tilde{\mu}_{\tilde{P}}^{u}\right]\right)
$$




$$
A(\tilde{P})=\frac{\left(\tilde{\mu}_{\tilde{P}}^{l}\right)^{2}-\sqrt{1-\left(\tilde{\mu}_{\tilde{P}}^{l}\right)^{2}-\left(\tilde{\nu}_{\tilde{P}}^{l}\right)^{2}}+\left(\tilde{\mu}_{\tilde{P}}^{u}\right)^{2}-\sqrt{1-\left(\tilde{\mu}_{\tilde{P}}^{u}\right)^{2}-\left(\tilde{\nu}_{\tilde{P}}^{u}\right)^{2}}}{2}, \quad A(\tilde{P}) \in[-1,1]
$$

Box I

$$
\begin{aligned}
\tilde{P}_{1} \oplus \tilde{P}_{2}= & \left\langle\left[\sqrt{\left(\tilde{\mu}_{\tilde{P}_{1}}^{l}\right)^{2}+\left(\tilde{\mu}_{\tilde{P}_{2}}^{l}\right)^{2}-\left(\tilde{\mu}_{\tilde{P}_{1}}^{l}\right)^{2}\left(\tilde{\mu}_{\tilde{P}_{2}}^{l}\right)^{2}},\right.\right. \\
& \left.\sqrt{\left(\tilde{\mu}_{\tilde{P}_{1}}^{u}\right)^{2}+\left(\tilde{\mu}_{\tilde{P}_{2}}^{u}\right)^{2}-\left(\tilde{\mu}_{\tilde{P}_{1}}^{u}\right)^{2}\left(\tilde{\mu}_{\tilde{P}_{2}}^{u}\right)^{2}}\right], \\
& {\left.\left[\tilde{\nu}_{\tilde{P}_{1}}^{l} \tilde{\nu}_{\tilde{P}_{2}}^{l}, \tilde{\nu}_{\tilde{P}_{1}}^{u} \tilde{\nu}_{\tilde{P}_{2}}^{u}\right]\right\rangle, }
\end{aligned}
$$

$$
\tilde{P}_{1} \otimes \tilde{P}_{2}=\left\langle\left[\tilde{\mu}_{\tilde{P}_{1}}^{l} \tilde{\mu}_{\tilde{P}_{2}}^{l}, \tilde{\mu}_{\tilde{P}_{1}}^{u} \tilde{\mu}_{\tilde{P}_{2}}^{u}\right]\right.
$$$$
\left[\sqrt{\left(\tilde{\nu}_{\tilde{P}_{1}}^{l}\right)^{2}+\left(\tilde{\nu}_{\tilde{P}_{2}}^{l}\right)^{2}-\left(\tilde{\nu}_{\tilde{P}_{1}}^{l}\right)^{2}\left(\tilde{\nu}_{\tilde{P}_{2}}^{l}\right)^{2}}\right.
$$$$
\sqrt{\left.\left.\left(\tilde{\nu}_{\tilde{P}_{1}}^{u}\right)^{2}+\left(\tilde{\nu}_{\tilde{P}_{2}}^{u}\right)^{2}-\left(\tilde{\nu}_{\tilde{P}_{1}}^{u}\right)^{2}\left(\tilde{\nu}_{\tilde{P}_{2}}^{u}\right)^{2}\right]\right\rangle}
$$

$$
\begin{aligned}
\lambda \tilde{P}= & {\left[\sqrt{1-\left(1-\left(\tilde{\mu}_{\tilde{P}}^{l}\right)^{2}\right)^{\lambda}}, \sqrt{1-\left(1-\left(\tilde{\mu}_{\tilde{P}}^{u}\right)^{2}\right)^{\lambda}}\right] } \\
& {\left[\left(\tilde{\nu}_{\tilde{P}}^{l}\right)^{\lambda},\left(\tilde{\nu}_{\tilde{P}}^{u}\right)^{\lambda}\right] }
\end{aligned}
$$

$$
\begin{aligned}
(\tilde{P})^{\lambda}= & {\left[\left(\tilde{\mu}_{\tilde{P}}^{l}\right)^{\lambda},\left(\tilde{\mu}_{\tilde{P}}^{u}\right)^{\lambda}\right] } \\
& {\left[\sqrt{1-\left(1-\left(\tilde{\nu}_{\tilde{P}}^{l}\right)^{2}\right)^{\lambda}}, \sqrt{1-\left(1-\left(\tilde{\nu}_{\tilde{P}}^{u}\right)^{2}\right)^{\lambda}}\right] }
\end{aligned}
$$

$$
\begin{gathered}
\left.\sqrt{1-\prod_{j=1}^{n}\left(1-\left(\tilde{\mu}_{\tilde{P}_{j}}^{u}\right)^{2}\right)^{w_{j}}}\right], \\
{\left[\prod_{j=1}^{n}\left(\tilde{\nu}_{\tilde{P}_{j}}^{l}\right)^{w_{j}}, \prod_{j=1}^{n}\left(\tilde{\nu}_{\tilde{P}_{j}}^{u}\right)^{w_{j}}\right],}
\end{gathered}
$$

where $w_{j}$ is the weight of $\tilde{P}_{j}(j=1,2, \cdots, n), w_{j} \in$ $[0,1]$, and $\sum_{j=1}^{n} w_{j}=1$.

Definition 5. Let $\tilde{P}_{j}=\left(\left[\tilde{\mu}_{\tilde{P}_{j}}^{l}, \tilde{\mu}_{\tilde{P}_{j}}^{u}\right],\left[\tilde{\nu}_{\tilde{P}_{j}}^{l}, \tilde{\nu}_{\tilde{P}_{j}}^{u}\right]\right)$ $(j=1,2)$ be two IVPFNs so that the distance between $\tilde{P}_{1}$ and $P_{2}$ can be determined, as defined by [17]:

$$
\begin{aligned}
& d\left(\tilde{P}_{1}, \tilde{P}_{2}\right)=\frac{1}{4}\left(\left|\left(\tilde{\mu}_{\tilde{P}_{1}}^{l}\right)^{2}-\left(\tilde{\mu}_{\tilde{P}_{2}}^{l}\right)^{2}\right|\right. \\
& +\left|\left(\tilde{\mu}_{\tilde{P}_{1}}^{u}\right)^{2}-\left(\tilde{\mu}_{\tilde{P}_{2}}^{u}\right)^{2}\right|+\left|\left(\tilde{\nu}_{\tilde{P}_{1}}^{l}\right)^{2}-\left(\tilde{\nu}_{\tilde{P}_{2}}^{l}\right)^{2}\right| \\
& +\left|\left(\tilde{\nu}_{\tilde{P}_{1}}^{u}\right)^{2}-\left(\tilde{\nu}_{\tilde{P}_{2}}^{u}\right)^{2}\right|+\left|\left(\tilde{\pi}_{\tilde{P}_{1}}^{l}\right)^{2}-\left(\tilde{\pi}_{\tilde{P}_{2}}^{l}\right)^{2}\right| \\
& \left.+\left|\left(\tilde{\pi}_{\tilde{P}_{1}}^{u}\right)^{2}-\left(\tilde{\pi}_{\tilde{P}_{2}}^{u}\right)^{2}\right|\right) .
\end{aligned}
$$

\section{Generalized entropy and knowledge measures for IVPFSs}

Fuzziness is known as a feature of imperfect knowledge and the lack of a clear distinction between the elements that are and are not members of a set. The fuzziness measure is mostly applied and cited in the literature as entropy [33]. Herein, we propose the measure of fuzziness for IVPFSs. To this end, the entropy measure proposed by Szmidt and Kacprzyk [33] is generalized to the IVPF environment. The proposed entropy is the result of the division of distances to the nearest and to the farthest crisp elements.

$$
\begin{aligned}
& I P F W A_{w}\left(\tilde{P}_{1}, \tilde{P}_{2}, \cdots, \tilde{P}_{n}\right) \\
& \quad=w_{1} \tilde{P}_{1} \oplus w_{2} \tilde{P}_{2} \oplus \cdots \oplus w_{n} \tilde{P}_{n} \\
& \quad=\left[\sqrt{1-\prod_{j=1}^{n}\left(1-\left(\tilde{\mu}_{\tilde{P}_{j}}^{l}\right)^{2}\right)^{w_{j}}},\right.
\end{aligned}
$$

Definition 6. Let $\tilde{P}=\left\{x,\left[\tilde{\mu}_{\tilde{p}}^{l}(x), \tilde{\mu}_{\tilde{p}}^{u}(x)\right],\left[\tilde{\nu}_{\tilde{p}}^{l}(x)\right.\right.$, $\left.\left.\tilde{\nu}_{\tilde{p}}^{u}(x)\right] \mid x \in X\right\}$ and $\widetilde{P}^{\prime}=\left\{x,\left[\tilde{\mu}_{\widetilde{P^{\prime}}}^{l}(x), \tilde{\mu}_{\widetilde{P^{\prime}}}^{u}(x)\right]\right.$, $\left.\left[\tilde{\nu}_{\widetilde{P}^{\prime}}^{l}(x), \tilde{\nu}_{\widetilde{P}^{\prime}}^{u}(x)\right] \mid x \in X\right\}$ be IVPFSs. Suppose that $E_{I V P F S}(\tilde{P})$ is a real-valued function. It is referred to 
as an entropy measure of $\tilde{P}$ if it satisfies the following axioms:

1. $E_{I V P F S}(\tilde{P})=0$ iff $\tilde{P}$ is a crisp set;

2. $E_{I V P F S}(\tilde{P})=1$ iff $\left[\tilde{\mu}_{\tilde{P}}^{l}(x), \tilde{\mu}_{\tilde{P}}^{u}(x)\right]=\left[\tilde{\nu}_{\tilde{P}}^{l}(x), \tilde{\nu}_{\tilde{P}}^{u}\right.$ $(x)] \forall x \in X$;

3. $E_{I V P F S}(\tilde{P})=E_{I V P F S}\left((\tilde{P})^{\complement}\right)$;

4. $E_{I V P F S}(\tilde{P}) \leq E_{I V P F S}\left(\widetilde{P^{\prime}}\right)$ if $\tilde{P} \subseteq \widetilde{P^{\prime}}$ for $\tilde{\mu}_{\widetilde{P^{\prime}}}^{l}(x) \leq$ $\tilde{\nu}_{\widetilde{P^{\prime}}}^{l}(x)$ and $\tilde{\mu}_{\widetilde{P^{\prime}}}^{u}(x) \leq \tilde{\nu}_{\widetilde{P^{\prime}}}^{u}(x)$ or $\widetilde{P^{\prime}} \subseteq \tilde{P}$ for $\tilde{\mu}_{\widetilde{P^{\prime}}}^{l}(x) \geq$ $\tilde{\nu}_{\widetilde{P}^{\prime}}^{l}(x)$ and $\tilde{\mu}_{\widetilde{P}^{\prime}}^{u}(x) \geq \tilde{\nu}_{\widetilde{P^{\prime}}}^{u}(x)$.

So, the definition of the generalized entropy measure for IVPFSs is presented by:

$$
\begin{aligned}
E_{I V P F S}(\tilde{P}) & =\frac{1}{n} \sum_{i=1}^{n} E_{I V P F S}\left(\tilde{P}\left(x_{i}\right)\right) \\
& =\frac{1}{n} \sum_{i=1}^{n} \frac{d\left(\tilde{P}\left(x_{i}\right), \tilde{P}^{\text {near }}\right)}{d\left(\tilde{P}\left(x_{i}\right), \tilde{P}^{\text {far }}\right)},
\end{aligned}
$$

where $d\left(\tilde{P}\left(x_{i}\right), \tilde{P}^{\text {near }}\right)$ denotes the distance from $\tilde{P}\left(x_{i}\right)$ to the nearest non-fuzzy value $\left(\tilde{P}^{\text {near }}=([1,1],[0,0]\right.$, $[0,0])$ or $([0,0],[1,1],[0,0]))$, and $d\left(\tilde{P}\left(x_{i}\right), \tilde{P}^{\mathrm{far}}\right)$ is the distance from $\tilde{P}\left(x_{i}\right)$ to the farthest non-fuzzy number $\left(\tilde{P}^{\mathrm{far}}=([1,1],[0,0],[0,0])\right.$ or $\left.([0,0],[1,1],[0,0])\right)$.

It should be noted that in some situations, the entropy measure defined above is not able to discriminate the fuzziness and the credibility of IVPFs. For instances, the IVPF values $\tilde{P}_{1}=([.7, .7],[.7, .7]$, $[\sqrt{.02}, \sqrt{.02}])$ and $\tilde{P}_{2}=([0,0],[0,0],[1,1])$ have equal entropy values, although the latter value has no information and in the former value, positive information is the same as negative one. The properly defined entropy measure should correctly differentiate these cases based on the scope of knowledge, which is useful in terms of decision-making. In this regard, an interesting measure of knowledge, introduced by Szmidt et al. [34], is employed considering both entropy measure and hesitation margin to capture the set of knowledge involved in IVPFSs as follows:

Definition 7. Let:

$$
\tilde{P}=\left\{x,\left(\left[\tilde{\mu}_{\tilde{P}}^{l}(x), \tilde{\mu}_{\tilde{P}}^{u}(x)\right], \quad\left[\tilde{\nu}_{\tilde{P}}^{l}(x), \tilde{\nu}_{\tilde{P}}^{u}(x)\right]\right) \mid x \in X\right\}
$$

be an IVPFS. The measure of knowledge for $\tilde{P}$ with $n$ elements is denoted by $K_{\mathrm{IVPFS}}(\tilde{P})$ and defined as follows:

$$
\begin{aligned}
& K_{\text {IVPFS }}(\tilde{P})=\frac{1}{n} \sum_{i=1}^{n}(1 \\
& \left.-\frac{\left[E_{I V P F S}\left(\tilde{P}\left(x_{i}\right)\right)+\left(\phi \tilde{\pi}_{\tilde{P}\left(x_{i}\right)}^{l}+(1-\phi) \tilde{\pi}_{\tilde{P}\left(x_{i}\right)}^{u}\right)\right]}{2}\right),
\end{aligned}
$$

where $E_{I V P F S}\left(\tilde{P}\left(x_{i}\right)\right)$ is the entropy of IVPFNs $\tilde{P}\left(x_{i}\right)$ and $\tilde{\pi}_{\tilde{P}\left(x_{i}\right)}^{l}$ and $\tilde{\pi}_{\tilde{P}\left(x_{i}\right)}^{u}$ are the lower and upper hesitation margins. The parameter $\phi \in[0,1]$ is an attitudinal character of the decision-maker. Suppose that $K_{I V P F S}(\tilde{P})$ is a real-valued function. It is referred to as a measure of knowledge for $\tilde{P}$ if it satisfies the following axioms:

1. $0 \leq K_{I V P F S}(\tilde{P}) \leq 1$;

2. $K_{I V P F S}(\tilde{P})=K_{I V P F S}\left((\tilde{P})^{\complement}\right)$;

3. $K_{I V P F S}(\tilde{P})=0$ iff $\left[\tilde{\mu}_{\tilde{P}}^{l}(x), \tilde{\mu}_{\tilde{P}}^{u}(x)\right]=\left[\tilde{\nu}_{\tilde{P}}^{l}(x)\right.$, $\left.\tilde{\nu}_{\tilde{P}}^{u}(x)\right]=[0,0]$

4. $K_{I V P F S}(\tilde{P})=1$ iff $\left[\tilde{\mu}_{\tilde{P}}^{l}(x), \tilde{\mu}_{\tilde{P}}^{u}(x)\right]=[0,0]$, $\left[\tilde{\nu}_{\tilde{P}}^{l}(x), \tilde{\nu}_{\tilde{P}}^{u}(x)\right]=[1,1]$ or $\left[\tilde{\mu}_{\tilde{P}}^{l}(x), \tilde{\mu}_{\tilde{P}}^{u}(x)\right]=[1,1]$,
$\left[\tilde{\nu}_{\tilde{P}}^{l}(x), \tilde{\nu}_{\tilde{P}}^{u}(x)\right]=[0,0]$. $\left[\tilde{\nu}_{\tilde{P}}^{l}(x), \tilde{\nu}_{\tilde{P}}^{u}(x)\right]=[0,0]$.

The proofs are straightforward.

\section{New IVPF-MCGDM approach with unknown expert and attribute weights for selecting the best sustainable transport project to fund}

This part initially develops an MCGDM problem under IVPF uncertainty. In the following, an extended form of VIKOR method is proposed for determining the weights of the DMs. Then, the maximizing deviation model aggregated with knowledge measure, as a measure of credibility of IVPFNs, is proposed to distinguish the weights of criteria. With regard to the weights of criteria and the weights of the DMs, an aggregated method is developed to select the best sustainable transport project to fund among a number of candidates.

\subsection{Problem formulation}

Assume an MCGDM problem under IVPF uncertainty; let $A=\left\{A_{1}, A_{2}, \cdots, A_{m}\right\}$ denote a discrete set of $m(m \geq 2)$ feasible candidates and let $C=$ $\left\{C_{1}, C_{2}, \cdots, C_{n}\right\}$ be a finite set of criteria. Let $E=$ $\left\{e_{1}, e_{2}, \cdots, e_{t}\right\}$ be a team of experts and let $\lambda=$ $\left(\lambda_{1}, \lambda_{2}, \cdots, \lambda_{t}\right)$ be the weight vector of experts, in which $0 \leq \lambda_{k} \leq 1$ and $\sum_{k=1}^{t} \lambda_{k}=1$. The weight 
vector of criteria for the expert $e_{k}$ is shown by $w^{k}=$ $\left(w_{1}^{k}, w_{2}^{k}, \cdots, w_{n}^{k}\right),(k=1,2, \cdots, t)$. As a matter of fact, in real-world problems for MCGDM, attribute and expert weighting data can be computed in advance. Because of such factors as time pressure, lack of enough knowledge, and vagueness of real-world problems in group settings, the data about attribute and expert weights are often totally unknown or at least not totally known. In this paper, it is assumed that the criteria weights are totally unknown or partially known in advance, and the experts' weights are totally unknown.

The expert $e_{k}$ uses the IVPFN $\tilde{\beta}_{i j}^{k}$ to show the criterion value of alternative $A_{i}$ while addressing the criterion $C_{j}$. Therefore, it is possible to address the MCGDM problem with IVPFNs exactly by applying the IVPF decision matrix as follows:

$$
\begin{gathered}
\mathscr{P}^{k}=\left(\tilde{\beta}_{i j}^{k}\right)_{m \times n}=\left(\tilde{P}\left(\left[\tilde{\mu}_{\tilde{\beta}_{i j}^{k}}^{l}, \tilde{\mu}_{\tilde{\beta}_{i j}^{k}}^{u}\right],\left[\tilde{\nu}_{\tilde{\beta}_{i j}^{k}}^{l}, \tilde{\nu}_{\tilde{\beta}_{i j}^{k}}^{u}\right]\right)\right)_{m \times n}, \\
(k=1,2, \cdots, t) .
\end{gathered}
$$

We use $\tilde{P}\left(\left[\tilde{\mu}_{\tilde{\beta}_{i j}^{k}}^{l}, \tilde{\mu}_{\tilde{\beta}_{i j}^{k}}^{u}\right],\left[\tilde{\nu}_{\tilde{\beta}_{i j}^{k}}^{l}, \tilde{\nu}_{\tilde{\beta}_{i j}^{k}}^{u}\right]\right)$ form to show the IVPF nature of values in the decision matrix.

Element $\tilde{\beta}_{i j}^{k}$ in the matrix $\mathscr{P}^{k}$ shows that the candidate $A_{i}$ is a very good alternative for the expert $e_{k}$ on the criterion $C_{j}$. This result comes with a margin of $\left[\tilde{\mu}_{\tilde{\beta}_{i j}^{k}}^{l}, \tilde{\mu}_{\tilde{\beta}_{i j}^{k}}^{u}\right]$, and the alternative $A_{i}$ is not a very good decision with a chance of $\left[\tilde{\nu}_{\tilde{\beta}_{i j}^{k}}^{l}, \tilde{\nu}_{\tilde{\beta}_{i j}^{k}}^{u}\right]$.

\subsection{Developed IVPF method for computing the weights of DMs}

In this section, a new method is developed to compute the DMs' weights.

Step A: Apply IVPFNs form to express each DM's preference for alternatives with respect to attributes and present the information concerning the decision is presented as a matrix, $\Psi^{k}$;

Step B: Determine the Positive Ideal Decision (PID) and the Negative Ideal Decision (NID) matrices. Consider a PID as the best group decision. $\Psi^{+}=$ $\left(\tilde{\psi}_{i j}^{+}\right)_{m \times n}$ is defined as the PID where $\tilde{\psi}_{i j}^{+}=$ $(1 / t) \sum_{k=1}^{t} \tilde{\psi}_{i j}^{k}$; therefore, we have:

$$
\begin{gathered}
\Psi^{+}=\left(\tilde{\psi}_{i j}^{+}\right)_{m \times n}=\left(\tilde{P}\left(\left[\tilde{\mu}_{\tilde{\psi}_{i j}^{+}}^{l}, \tilde{\mu}_{\tilde{\psi}_{i j}^{+}}^{u}\right],\left[\tilde{\nu}_{\tilde{\psi}_{i j}^{+}}^{l}, \tilde{\nu}_{\tilde{\psi}_{i j}^{+}}^{u}\right]\right)\right)_{m \times n}, \\
(k=1,2, \cdots, t) .
\end{gathered}
$$

By Definition 4 we have:

$$
\tilde{\mu}_{\tilde{\psi}_{i j}^{+}}^{l}=\sqrt{1-\prod_{k=1}^{t}\left(1-\left(\tilde{\mu}_{\tilde{\psi}_{i j}^{k}}^{l}\right)^{2}\right)^{1 / t}}
$$

$$
\begin{aligned}
& \tilde{\mu}_{\tilde{\psi}_{i j}^{+}}^{u}=\sqrt{1-\prod_{k=1}^{t}\left(1-\left(\tilde{\mu}_{\tilde{\psi}_{i j}^{k}}^{u}\right)^{2}\right)^{1 / t}} \\
& \tilde{\nu}_{\tilde{\psi}_{i j}^{+}}^{l}=\prod_{k=1}^{t}\left(\tilde{\nu}_{\tilde{\psi}_{i j}^{k}}^{l}\right)^{1 / t}, \quad \tilde{\nu}_{\tilde{\psi}_{i j}^{+}}^{u}=\prod_{k=1}^{t}\left(\tilde{\nu}_{\tilde{\psi}_{i j}^{k}}^{u}\right)^{1 / t}
\end{aligned}
$$

and:

$$
(i \in M, j \in N, k \in T) \text {. }
$$

An NID of all individual decisions needs to have maximum separation from the PID. As a result, the minimum decision of all individual decisions is computed as an NID as follows:

$$
\begin{aligned}
\Psi_{\min }^{-}= & \left(\tilde{\psi}_{\min _{i j}}^{-}\right)_{m \times n}=\left(\tilde { P } \left(\left[\tilde{\mu}_{\tilde{\psi}_{\min _{i j}}^{-}}^{l}, \tilde{\mu}_{\tilde{\psi}_{\min _{i j}}^{-}}^{u}\right]\right.\right. \\
& {\left.\left.\left[\tilde{\nu}_{\tilde{\psi}_{\min _{i j}}^{-}}^{l}, \tilde{\nu}_{\tilde{\psi}_{\min _{i j}}^{-}}^{u}\right]\right)\right)_{m \times n}, }
\end{aligned}
$$

where:

$$
\begin{array}{ll}
\tilde{\mu}_{\tilde{\psi}_{\min _{i j}}^{-}}^{l}=\min _{k \in T}\left\{\tilde{\mu}_{\tilde{\psi}_{i j}^{k}}^{l}\right\}, & \tilde{\mu}_{\tilde{\psi}_{\min _{i j}}^{u}}^{u}=\min _{k \in T}\left\{\tilde{\mu}_{\tilde{\psi}_{i j}^{k}}^{u}\right\}, \\
\tilde{\nu}_{\tilde{\psi}_{\min _{i j}}^{-}}^{l}=\max _{k \in T}\left\{\tilde{\nu}_{\tilde{\psi}_{i j}^{k}}^{l}\right\}, & \tilde{\nu}_{\tilde{\psi}_{\min _{i j}}^{-}}^{u}=\max _{k \in T}\left\{\tilde{\nu}_{\tilde{\psi}_{i j}^{k}}^{u}\right\},
\end{array}
$$

and:

$$
i \in M, \quad j \in N, \quad k \in T \text {. }
$$

We can define the maximum decision of all individual decisions as an NID as follows:

$$
\begin{aligned}
\Psi_{\max }^{-}= & \left(\tilde{\psi}_{\max _{i j}}^{-}\right)_{m \times n}=\left(\tilde { P } \left(\left[\tilde{\mu}_{\left.\tilde{\psi}_{\max _{i j}}^{-}, \tilde{\mu}_{\tilde{\psi}_{\max _{i j}}^{-}}^{u}\right]}\right.\right.\right. \\
& {\left.\left.\left[\tilde{\nu}_{\tilde{\psi}_{\max _{i j}}^{-},}^{l}, \tilde{\nu}_{\tilde{\psi}_{\max _{i j}}^{u}}^{u}\right]\right)\right)_{m \times n}, }
\end{aligned}
$$

where:

$$
\begin{aligned}
& \tilde{\mu}_{\tilde{\psi}_{\text {max }_{i j}^{-}}^{l}}^{l}=\max _{k \in T}\left\{\tilde{\mu}_{\tilde{\psi}_{i j}^{k}}^{l}\right\}, \quad \tilde{\mu}_{\tilde{\psi}_{\text {max }}^{-}{ }_{i j}}^{u}=\max _{k \in T}\left\{\tilde{\mu}_{\tilde{\psi}_{i j}^{k}}^{u}\right\}, \\
& \tilde{\nu}_{\tilde{\psi}_{\max _{i j}}^{-}}^{l}=\min _{k \in T}\left\{\tilde{\nu}_{\tilde{\psi}_{i j}^{k}}^{l}\right\}, \quad \tilde{\nu}_{\tilde{\psi}_{\max _{i j}}^{-}}^{u}=\min _{k \in T}\left\{\tilde{\nu}_{\tilde{\psi}_{i j}^{k}}^{u}\right\},
\end{aligned}
$$

and:

$$
i \in M, \quad j \in N, \quad k \in T .
$$

Similarly, the complement $\left(\Psi^{+}\right)^{\mathcal{C}}$ of $\Psi^{+}$needs to have maximum separation from the PID, $\Psi^{+}$. Consequently, another NID has to be assumed.

$$
\begin{aligned}
\Psi_{C}^{-} & =\left(\tilde{\psi}_{C_{i j}}^{-}\right)_{m \times n}=\left(\Psi^{+}\right)^{C} \\
& =\left(\tilde{P}\left(\left[\tilde{\nu}_{\tilde{\psi}_{i j}^{+}}^{l}, \tilde{\nu}_{\tilde{\psi}_{i j}^{+}}^{u}\right],\left[\tilde{\mu}_{\tilde{\psi}_{i j}^{+}}^{l}, \tilde{\mu}_{\tilde{\psi}_{i j}^{+}}^{u}\right]\right)\right)_{m \times n},
\end{aligned}
$$

where: 


$$
\begin{aligned}
& \tilde{\mu}_{\tilde{\psi}_{C_{i j}}}^{l}=\prod_{k=1}^{t}\left(\tilde{\nu}_{\tilde{\psi}_{i j}^{k}}^{l}\right)^{1 / t}, \quad \tilde{\mu}_{\tilde{\psi}_{C_{i j}}}^{u}=\prod_{k=1}^{t}\left(\tilde{\nu}_{\tilde{\psi}_{i j}^{k}}^{u}\right)^{1 / t}, \\
& \tilde{\nu}_{\tilde{\psi}_{C_{i j}}^{l}}^{l}=\sqrt{1-\prod_{k=1}^{t}\left(1-\left(\tilde{\mu}_{\tilde{\psi}_{i j}^{k}}^{l}\right)^{2}\right)^{1 / t}} \\
& \tilde{\nu}_{\tilde{\psi}_{C_{i j}}^{u}}^{u} \\
& =\sqrt{1-\prod_{k=1}^{t}\left(1-\left(\tilde{\mu}_{\tilde{\psi}_{i j}^{k}}^{u}\right)^{2}\right)^{1 / t}}
\end{aligned}
$$

and:

$$
i \in M, \quad j \in N, \quad k \in T \text {. }
$$

Step C: Compute the values $S_{k}$ and $R_{k}$ :

$$
\begin{aligned}
& S_{k}=\sum_{i=1}^{m} \sum_{j=1}^{n} \\
& \frac{d\left(\tilde{\psi}_{i j}^{+}, \tilde{\psi}_{i j}^{k}\right)}{d\left(\tilde{\psi}_{i j}^{+}, \tilde{\psi}_{\min _{i j}}^{-}\right)+d\left(\tilde{\psi}_{i j}^{+}, \tilde{\psi}_{\max _{i j}}^{-}\right)+d\left(\tilde{\psi}_{i j}^{+}, \tilde{\psi}_{C_{i j}}^{-}\right)}, \\
& R_{k}=\max _{i, j} d\left(\tilde{\psi}_{i j}^{+}, \tilde{\psi}_{i j}^{k}\right) \\
& \frac{d\left(\tilde{\psi}_{i j}^{+}, \tilde{\psi}_{\min _{i j}}^{-}\right)+d\left(\tilde{\psi}_{i j}^{+}, \tilde{\psi}_{\max _{i j}}^{-}\right)+d\left(\tilde{\psi}_{i j}^{+}, \tilde{\psi}_{C_{i j}}^{-}\right)}{d}
\end{aligned}
$$

where $d\left(\tilde{\psi}_{i j}^{+}, \tilde{\psi}_{i j}^{k}\right), d\left(\tilde{\psi}_{i j}^{+}, \tilde{\psi}_{\min _{i j}}^{-}\right), d\left(\tilde{\psi}_{i j}^{+}, \tilde{\psi}_{\max _{i j}}^{-}\right)$, and $d\left(\tilde{\psi}_{i j}^{+}, \tilde{\psi}_{C_{i j}}\right)$ are calculated orderly in Definition 5;

Step D: compute the values $Q_{k}$ :

$$
Q_{k}=\vartheta \frac{\left(S_{k}-S^{+}\right)}{\left(S^{-}-S^{+}\right)}+(1-\vartheta) \frac{\left(R_{k}-R^{+}\right)}{\left(R^{-}-R^{+}\right)},
$$

where:

$$
\begin{aligned}
S^{+} & =\min _{k} S_{k}, & S^{-} & =\max _{k} S_{k}, \\
R^{+} & =\min _{k} R_{k}, & R^{-} & =\max _{k} R_{k} .
\end{aligned}
$$

$\vartheta$ denotes the weight of the strategy set by the majority and $1-\vartheta$ shows the weight of the strategy of a minimum of the individual regret;

Step E: Calculate the weight of all DMs based on $Q_{k}$. The weight of the $k$ th $(k \in T)$ DM can be obtained as follows:

$$
\lambda_{k}=\frac{\left(1-Q_{k}\right)}{\sum_{k=1}^{t}\left(1-Q_{k}\right)},
$$

such that $\lambda_{k} \geq 0, \sum_{k=1}^{t} \lambda_{k}=1$.

\subsection{Developed IVPF method for computing the criteria weights}

In the decision-making process, if one attribute is known to have a similar assessment value among candidates, it should be assigned a smaller weight value; otherwise, the attribute that causes significant deviations must be evaluated with a larger weight, contrary to its amount of importance [24]. To do so, an optimal model $\left(M_{-} 1\right)$ is applied which maximizes all deviation values for all the criteria to choose the weight vector $w^{k}$. This is carried out as follows:

$$
\left(M \_1\right)\left\{\begin{array}{l}
\max D V=\sum_{j=1}^{n} w_{j}^{k} \sum_{i=1}^{m} \sum_{l=1}^{m} d\left(\tilde{\beta}_{i j}^{k}, \tilde{\beta}_{l j}^{k}\right) \\
\text { s.t. } \sum_{j=1}^{n}\left(w_{j}^{k}\right)^{2}=1, \quad w_{j}^{k} \geq 0, \\
\quad j=1,2, \cdots, n
\end{array}\right.
$$

It should be noted that this deviation-based model for evaluating weights of attributes only considers the discrimination of assessments. The credibility of fuzzy assessments in the decision matrix is neglected. A knowledge measure of IVPFNs can be applied to comprehensively consider the credibility of the decision preference in the process of allocating attribute weights more reasonably. Hence, the following model is constructed by integrating the knowledge measure in $\left(M_{-} 1\right)$ to determine the weights of attributes if the information concerning them is totally unknown:

$$
\left(M \_2\right)\left\{\begin{array}{c}
\max F\left(w^{k}\right)=\sum_{j=1}^{n} F_{j}\left(w^{k}\right) \\
=\sum_{j=1}^{n} w_{j}^{k}\left(\sum_{i=1}^{m}\left(\sum_{l=1}^{m} d\left(\tilde{\beta}_{i j}^{k}, \tilde{\beta}_{l j}^{k}\right)\right)\right. \\
\left.+K_{I V P F S}\left(\tilde{\beta}_{i j}^{k}\right)\right) \\
\text { s.t. } \sum_{j=1}^{n}\left(w_{j}^{k}\right)^{2}=1, \quad w_{j}^{k} \geq 0, \\
j=1,2, \cdots, n
\end{array}\right.
$$

By solving the proposed model, we can construct the linguistic function:

$$
\begin{gathered}
L\left(w_{j}^{k}, \xi\right)=\sum_{j=1}^{n} w_{j}^{k}\left(\sum_{i=1}^{m}\left(\sum_{l=1}^{m} d\left(\tilde{\beta}_{i j}^{k}, \tilde{\beta}_{l j}^{k}\right)\right)\right. \\
\left.+K_{I V P F S}\left(\tilde{\beta}_{i j}^{k}\right)\right)+\frac{\xi}{2}\left(\sum_{j=1}^{n}\left(w_{j}^{k}\right)^{2}-1\right),
\end{gathered}
$$

where $\xi$ is a linguistic multiplier.

Then, differentiating Eq. (22) while considering $w_{j}^{k}(j=1,2, \cdots, n)$ and $\xi$ and determining these partial derivatives as zero result in obtaining the following set of equations: 


$$
\left\{\begin{array}{c}
\frac{d l}{d w_{j}^{k}}=\sum_{j=1}^{n}\left(\sum_{i=1}^{m}\left(\sum_{l=1}^{m} d\left(\tilde{\beta}_{i j}^{k}, \tilde{\beta}_{l j}^{k}\right)\right)\right. \\
\left.\quad+K_{I V P F S}\left(\tilde{\beta}_{i j}^{k}\right)\right)+\xi w_{j}^{k}=0 \\
\frac{d l}{d \xi}=\sum_{j=1}^{n}\left(w_{j}^{k}\right)^{2}-1=0
\end{array}\right.
$$

By solving Eq. (23), an exact relation used to compute the normalized attribute weights is obtained and presented by:

$$
w_{j}^{k}=\frac{\sum_{i=1}^{m}\left(\sum_{l=1}^{m} d\left(\tilde{\beta}_{i j}^{k}, \tilde{\beta}_{l j}^{k}\right)\right)+K_{I V P F S}\left(\tilde{\beta}_{i j}^{k}\right)}{\sum_{j=1}^{n} \sum_{i=1}^{m}\left(\sum_{l=1}^{m} d\left(\tilde{\beta}_{i j}^{k}, \tilde{\beta}_{l j}^{k}\right)\right)+K_{I V P F S}\left(\tilde{\beta}_{i j}^{k}\right)} .
$$

We can construct another model for calculating an optimal attribute weighting vector in situations where DMs can provide incomplete attribute weighting information as follows:

$$
\left(M \_3\right)\left\{\begin{array}{c}
\max F\left(w^{k}\right)=\sum_{j=1}^{n} F_{j}\left(w^{k}\right) \\
=\sum_{j=1}^{n} w_{j}^{k}\left(\sum_{i=1}^{m}\left(\sum_{l=1}^{m} d\left(\tilde{\beta}_{i j}^{k}, \tilde{\beta}_{l j}^{k}\right)\right)\right. \\
\left.\quad+K_{I V P F S}\left(\tilde{\beta}_{i j}^{k}\right)\right) \\
\text { s.t. } w^{k} \in H, \quad \sum_{j=1}^{n}\left(w_{j}^{k}\right)^{2}=1, \quad w_{j}^{k} \geq 0, \\
j=1,2, \cdots, n
\end{array}\right.
$$

where $H$ indicates the incomplete attribute weighting information. The known weight information on the criteria is categorized into five basic ranking forms as presented in [35].

Model $\left(M \_3\right)$ can also be solved by the linguistic method and the corresponding optimal solution $w^{k}=\left(w_{1}^{k}, w_{2}^{k}, \cdots, w_{n}^{k}\right),(k=1,2, \cdots, t)$ can also be normalized as an attribute weighting vector similar to Eq. (24).

\subsection{Integrated approach to the IVPF-MCGDM method}

In this subsection, an effective approach to solving MCGDM problems under IVPF environment is structured based on the extension of the VIKOR method.

Step 1: If the expert $e_{k}$ has totally unknown information about the attribute weights, then the attribute weights are gathered by solving Model $\left(M \_2\right)$ and applying Eq. (24), whereas if the information concerning the attribute weights for the expert $e_{k}$ is not completely unknown and, in fact, is partially known, Model ( $M \_3$ ) is solved to compute the weight vector of attributes $w^{k}=\left(w_{1}^{k}, w_{2}^{k}, \cdots, w_{n}^{k}\right),(k=$ $1,2, \cdots, t)$.

Step 2: Create the weighted IVPF decision matrix for each expert by applying the multiplication operator on $\mathscr{P}^{k}=\left(\tilde{\beta}_{i j}^{k}\right)_{m \times n}$ and $w^{k}=\left(w_{1}^{k}, w_{2}^{k}, \cdots, w_{n}^{k}\right)$

$$
\begin{aligned}
\Psi^{k} & =\left(\tilde{\psi}_{i j}^{k}\right)_{m \times n} \\
& =\left(\tilde{P}\left(\left[\tilde{\mu}_{\tilde{\psi}_{i j}^{k}}^{l}, \tilde{\mu}_{\tilde{\psi}_{i j}^{k}}^{u}\right],\left[\tilde{\nu}_{\tilde{\psi}_{i j}^{k}}^{l}, \tilde{\nu}_{\tilde{\psi}_{i j}^{k}}^{u}\right]\right)\right)_{m \times n},
\end{aligned}
$$

where $\tilde{\psi}_{i j}^{k}=w_{j}^{k} \tilde{\beta}_{i j}^{k}$; thus, by Definition 5 we have:

$$
\begin{aligned}
& \tilde{\mu}_{\tilde{\psi}_{i j}^{k}}^{l}=\sqrt{1-\left(1-\left(\tilde{\mu}_{\tilde{\beta}_{i j}^{k}}^{l}\right)^{2}\right)^{w_{j}^{k}}}, \\
& \tilde{\mu}_{\tilde{\psi}_{i j}^{k}}^{u}=\sqrt{1-\left(1-\left(\tilde{\mu}_{\tilde{\beta}_{i j}^{k}}^{u}\right)^{2}\right)^{w_{j}^{k}}}, \\
& \tilde{\nu}_{\tilde{\psi}_{i j}^{k}}^{l}=\left(\tilde{\nu}_{\tilde{\beta}_{i j}^{k}}^{l}\right)^{w_{j}^{k}}, \quad \tilde{\nu}_{\tilde{\psi}_{i j}^{k}}^{u}=\left(\tilde{\nu}_{\tilde{\beta}_{i j}^{k}}^{u}\right)^{w_{j}^{k}},
\end{aligned}
$$

and:

$$
\begin{aligned}
& (i=\{1,2, \cdots, m\}, \quad j=\{1,2, \cdots, n\}, \\
& k=\{1,2, \cdots, t\}) .
\end{aligned}
$$

Step 3: Compute the weighting vector of the experts $\lambda=\left(\lambda_{1}, \lambda_{2}, \cdots, \lambda_{t}\right)$ by using the new approach proposed in Subsection 4.2, Steps A-E.

Step 4: Aggregate all the weighted IVPF decision matrices $\Psi^{k}$ into the overall group IVPF decision matrix by applying IPFWA $A_{w}$ operator to $\Psi^{k}=$ $\left(\tilde{\psi}_{i j}^{k}\right)_{m \times n}$ and $\lambda=\left(\lambda_{1}, \lambda_{2}, \cdots, \lambda_{t}\right)$ :

$\Psi=\left(\tilde{\psi}_{i j}\right)_{m \times n}=\left(\tilde{P}\left(\left[\tilde{\mu}_{\tilde{\psi}_{i j}}^{l}, \tilde{\mu}_{\tilde{\psi}_{i j}}^{u}\right],\left[\tilde{\nu}_{\tilde{\psi}_{i j}}^{l}, \tilde{\nu}_{\tilde{\psi}_{i j}}^{u}\right]\right)\right)_{m \times n}$

where:

$$
\tilde{\psi}_{i j}=\sum_{k=1}^{t} \lambda_{k} \tilde{\psi}_{i j}^{k}
$$

Thus, by Definition $6, \tilde{\psi}_{i j}$ is computed by:

$$
\begin{aligned}
\tilde{\psi}_{i j} & =\operatorname{IPFW} A_{w}\left(\tilde{\psi}_{i j}^{1}, \tilde{\psi}_{i j}^{2}, \cdots, \tilde{\psi}_{i j}^{t}\right) \\
& =\lambda_{1} \tilde{\psi}_{i j}^{1} \oplus \lambda_{2} \tilde{\psi}_{i j}^{2} \oplus \cdots \oplus \lambda_{t} \tilde{\psi}_{i j}^{t} \\
& =\sqrt{1-\prod_{k=1}^{t}\left(1-\left(\tilde{\mu}_{\tilde{\psi}_{i j}^{k}}^{l}\right)^{2}\right)^{\lambda_{k}}},
\end{aligned}
$$




$$
\begin{aligned}
& \left.\sqrt{1-\prod_{k=1}^{t}\left(1-\left(\tilde{\mu}_{\tilde{\psi}_{i j}^{k}}^{u}\right)^{2}\right)^{\lambda_{k}}}\right], \\
& {\left[\prod_{k=1}^{t}\left(\tilde{\nu}_{\tilde{\psi}_{i j}^{k}}^{l}\right)^{\lambda_{k}}, \prod_{k=1}^{t}\left(\tilde{\nu}_{\tilde{\psi}_{i j}^{k}}^{u}\right)^{\lambda_{k}}\right],} \\
& (i=\{1,2, \cdots, m\}, \quad j=\{1,2, \cdots, n\}, \\
& k=\{1,2, \cdots, t\}) .
\end{aligned}
$$

Step 5: Form the normalized decision matrix of the IVPF overall performance by the following presented approach. Categorize the set of attributes into two main groups, the groups of benefit and cost, which are presented by $B$ and $C$, respectively.

$$
\overline{\tilde{\psi}_{i j}}= \begin{cases}\tilde{\psi}_{i j} ; & j \in B \\ \left(\tilde{\psi}_{i j}\right)^{\complement} ; & j \in C\end{cases}
$$

where is the complement of $\tilde{\psi}_{i j}$. Thus, we can obtain the normalized decision matrix:

$$
\begin{aligned}
\bar{\Psi} & =\left(\overline{\tilde{\psi}_{i j}}\right)_{m \times n} \\
& =\left(\tilde{P}\left(\left[\tilde{\mu} \frac{l}{\tilde{\psi}_{i j}}, \tilde{\mu} \frac{u}{\tilde{\psi}_{i j}}\right],\left[\tilde{\nu} \frac{l}{\tilde{\psi}_{i j}}, \tilde{\nu} \frac{u}{\tilde{\psi}_{i j}}\right]\right)\right)_{m \times n} .
\end{aligned}
$$

Step 6: Compute the values $S_{i}$ and $R_{i}$ by:

$$
\begin{aligned}
& \tilde{S}_{i}=\sum_{j=1}^{n} \overline{\tilde{\psi}_{i j}}, \\
& \tilde{R}_{i}=\max _{j} \overline{\tilde{\psi}_{i j}},
\end{aligned}
$$

where $\tilde{S}_{i}$ and $\tilde{R}_{i}$ are used for formulating the measure of the group utility and individual regret, respectively.

Step 7: Defuzzify the values of $\tilde{S}_{i}$ and $\tilde{R}_{i}$ using the improved accuracy function introduced in Definition 2.

Step 8: Calculate the values of $Q_{i}$ by:

$$
\begin{aligned}
Q_{i}= & \left(\frac{S^{-}-S^{+}}{S^{-}-S^{+}+R^{-}-R^{+}}\right) \frac{\left(S_{i}-S^{+}\right)}{\left(S^{-}-S^{+}\right)} \\
& +\left(\frac{R^{-}-R^{+}}{S^{-}-S^{+}+R^{-}-R^{+}}\right) \frac{\left(R_{i}-R^{+}\right)}{\left(R^{-}-R^{+}\right)},
\end{aligned}
$$

where:

$$
\begin{array}{ll}
S^{+}=\min _{i} S_{i}, & S^{-}=\max _{i} S_{i}, \\
R^{+}=\min _{i} R_{i}, & R^{-}=\max _{i} R_{i} .
\end{array}
$$

$\frac{S^{-}-S^{+}}{S^{-}-S^{+}+R^{-}-R^{+}}$is used to present the weight of the strategy of the majority, while $\frac{R^{-}-R^{+}}{S^{-}-S^{+}+R^{-}-R^{+}}$is used to show the weight of the strategy of the least value of the individual regret.

In the developed ranking index, the values of $\frac{S^{-}-S^{+}}{S^{-}-S^{+}+R^{-}-R^{+}}$and $\frac{R^{-}-R^{+}}{S^{-}-S^{+}+R^{-}-R^{+}}$are determined by the distances $R^{-}-R^{+}$and $S^{-}-S^{+}$. The main advantage of the proposed method is its simplicity and there is no need to calculate the $\vartheta$ value of the traditional VIKOR method for all cases.

Step 9: Rank the alternatives by sorting the values of $Q_{i}$ in descending order.

The structure of the proposed IVPF-MCGDM method is given in Figure 2.

\section{Case study}

In this section, the proposed approach is applied to a real case study of an Iranian transport complex to prove its applicability to solving sustainable transport investment decision problems. To address the issue, a group of three decision-makers is asked to evaluate four alternative transport investments based on ten main criteria. The criteria used for evaluation are based on a comprehensive review of some of the recent studies on this subject $[36,37]$. Therefore, Table 1 displays them. Due to the confidentiality of the information, only limited project details are presented.

Assuming that the experts' weight vectors and the criteria weights are totally unknown, the evaluated value of candidates while considering criteria

Table 1. Criteria evaluation of three factors in sustainability.

\begin{tabular}{ll}
\hline $\begin{array}{l}\text { Perspective of } \\
\text { sustainability }\end{array}$ & Criteria \\
\hline
\end{tabular}

Return on investment

Economic Financial risk

Reduction in costs

Safety

Social

Affordability

Employment

Basic accessibility

Greenhouse gas emissions

Environmental Climate and global warming

Resource efficiency 


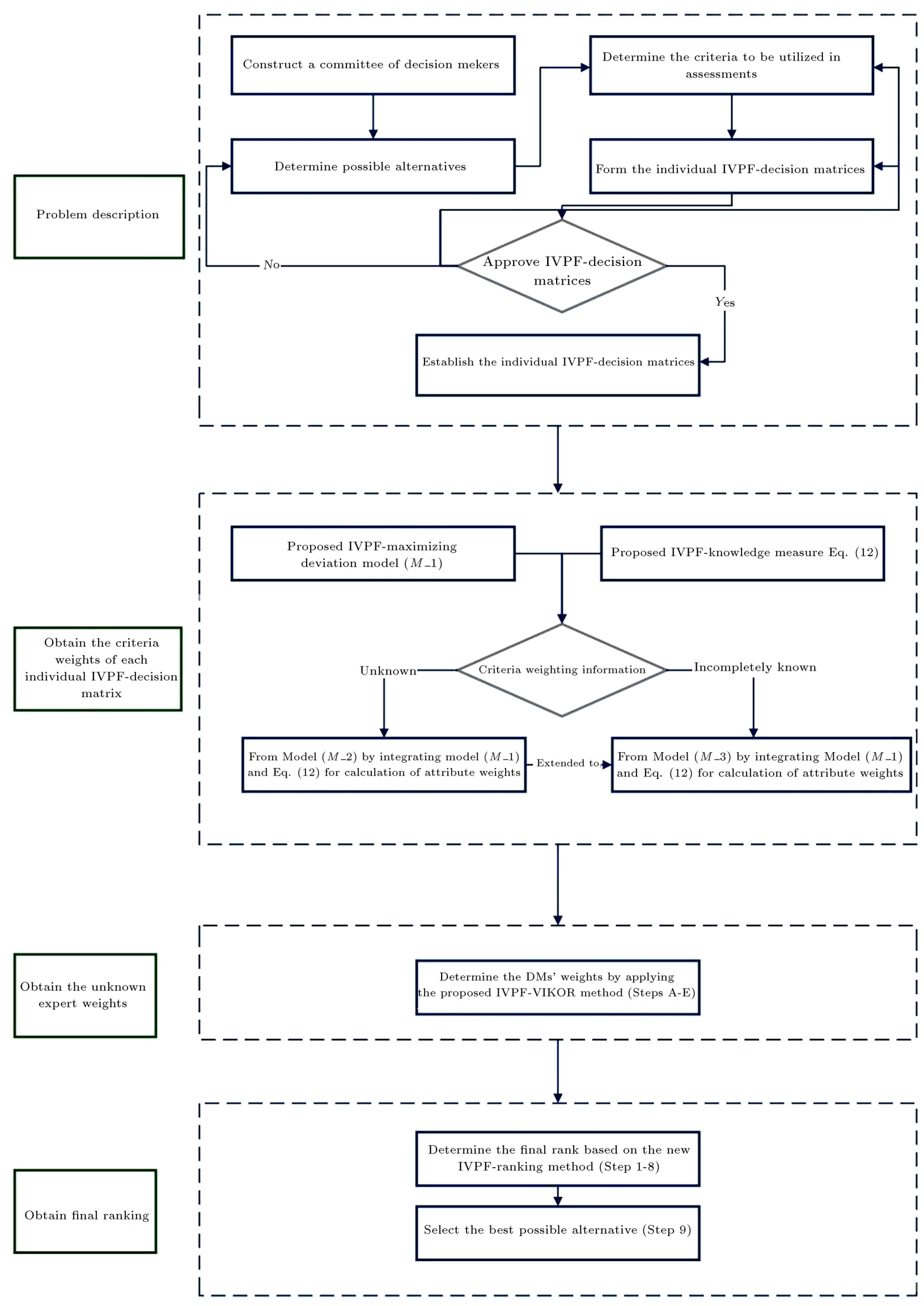

Figure 2. Comprehensive structure of the proposed IVPF-MCGDM method. 
Table 2. Linguistic terms used to assess the alternatives [30].

\begin{tabular}{lc}
\hline Linguistic variables & IVF-numbers \\
\hline Very Poor $(\mathrm{VP})$ & $([0.1,0.2],[0.8,0.9])$ \\
Poor $(\mathrm{P})$ & $([0.2,0.3],[0.7,0.8])$ \\
Moderately Poor $(\mathrm{MP})$ & $([0.3,0.4],[0.6,0.7])$ \\
Fair $(\mathrm{F})$ & $([0.5,0.6],[0.4,0.5])$ \\
Good $(\mathrm{G})$ & $([0.7,0.8],[0.2,0.3])$ \\
Very Good $(\mathrm{VG})$ & $([0.8,0.9],[0.1,0.2])$ \\
\hline
\end{tabular}

Table 3. Obtained judgments of $E_{1}$.

\begin{tabular}{ccccc}
\hline Criteria & $\boldsymbol{A}_{\mathbf{1}}$ & $\boldsymbol{A}_{\mathbf{2}}$ & $\boldsymbol{A}_{\mathbf{3}}$ & $\boldsymbol{A}_{\mathbf{4}}$ \\
\hline$C_{1}$ & $\mathrm{G}$ & $\mathrm{F}$ & $\mathrm{VG}$ & $\mathrm{VG}$ \\
$C_{2}$ & $\mathrm{~F}$ & $\mathrm{MG}$ & $\mathrm{MG}$ & $\mathrm{F}$ \\
$C_{3}$ & $\mathrm{G}$ & $\mathrm{MP}$ & $\mathrm{MP}$ & $\mathrm{VG}$ \\
$C_{4}$ & $\mathrm{VG}$ & $\mathrm{G}$ & $\mathrm{G}$ & $\mathrm{MP}$ \\
$C_{5}$ & $\mathrm{MP}$ & $\mathrm{MP}$ & $\mathrm{MG}$ & $\mathrm{G}$ \\
$C_{6}$ & $\mathrm{MP}$ & $\mathrm{P}$ & $\mathrm{F}$ & $\mathrm{VG}$ \\
$C_{7}$ & $\mathrm{G}$ & $\mathrm{G}$ & $\mathrm{G}$ & $\mathrm{VG}$ \\
$C_{8}$ & $\mathrm{VG}$ & $\mathrm{MP}$ & $\mathrm{F}$ & $\mathrm{VP}$ \\
$C_{9}$ & $\mathrm{G}$ & $\mathrm{MP}$ & $\mathrm{F}$ & $\mathrm{P}$ \\
$C_{10}$ & $\mathrm{VG}$ & $\mathrm{F}$ & $\mathrm{G}$ & $\mathrm{VP}$ \\
\hline
\end{tabular}

are directly provided by judgments of experts. This judgment is in the form of linguistic assessments presented in Table 2. Then, the linguistic variables presented in this table are converted into IVPFSs. This is done to address the uncertainty of criteria values with more flexibility. It should be noted that the aforementioned converted values are given in Table 2 .

Tables 3 to 5 provide the decision matrices of the evaluation problem. It should be noted that the evaluation criteria are stated as benefit or cost criteria. The benefit criteria consist of $C_{1}, C_{3}, C_{4}, C_{5}, C_{6}, C_{7}$, $C_{8}, C_{9}$, and $C_{10}$. The cost criteria include $C_{2}$. Projects are denoted by $A_{1}, A_{2}, A_{3}$, and $A_{4}$ and experts are referred to as $E_{1}, E_{2}$, and $E_{3}$.

In situations with completely unknown information about attributes' weights and weight vector of experts, the decision steps can be detailed as follows:
Table 4. Obtained judgments of $E_{2}$.

\begin{tabular}{ccccc}
\hline Criteria & $\boldsymbol{A}_{\mathbf{1}}$ & $\boldsymbol{A}_{\mathbf{2}}$ & $\boldsymbol{A}_{\mathbf{3}}$ & $\boldsymbol{A}_{\mathbf{4}}$ \\
\hline$C_{1}$ & $\mathrm{VG}$ & $\mathrm{G}$ & $\mathrm{G}$ & $\mathrm{G}$ \\
$C_{2}$ & $\mathrm{MG}$ & $\mathrm{F}$ & $\mathrm{MG}$ & $\mathrm{MG}$ \\
$C_{3}$ & $\mathrm{MG}$ & $\mathrm{F}$ & $\mathrm{F}$ & $\mathrm{G}$ \\
$C_{4}$ & $\mathrm{VG}$ & $\mathrm{F}$ & $\mathrm{MG}$ & $\mathrm{P}$ \\
$C_{5}$ & $\mathrm{~F}$ & $\mathrm{MP}$ & $\mathrm{F}$ & $\mathrm{G}$ \\
$C_{6}$ & $\mathrm{MP}$ & $\mathrm{P}$ & $\mathrm{MP}$ & $\mathrm{G}$ \\
$C_{7}$ & $\mathrm{G}$ & $\mathrm{MG}$ & $\mathrm{VG}$ & $\mathrm{G}$ \\
$C_{8}$ & $\mathrm{VG}$ & $\mathrm{F}$ & $\mathrm{MG}$ & $\mathrm{VP}$ \\
$C_{9}$ & $\mathrm{VG}$ & $\mathrm{MP}$ & $\mathrm{G}$ & $\mathrm{MP}$ \\
$C_{10}$ & $\mathrm{VG}$ & $\mathrm{MG}$ & $\mathrm{MG}$ & $\mathrm{VP}$ \\
\hline
\end{tabular}

Table 5. Obtained judgments of $E_{3}$.

\begin{tabular}{ccccc}
\hline Criteria & $\boldsymbol{A}_{\mathbf{1}}$ & $\boldsymbol{A}_{\mathbf{2}}$ & $\boldsymbol{A}_{\mathbf{3}}$ & $\boldsymbol{A}_{\mathbf{4}}$ \\
\hline$C_{1}$ & $\mathrm{G}$ & $\mathrm{F}$ & $\mathrm{G}$ & $\mathrm{VG}$ \\
$C_{2}$ & $\mathrm{~F}$ & $\mathrm{~F}$ & $\mathrm{~F}$ & $\mathrm{MG}$ \\
$C_{3}$ & $\mathrm{~F}$ & $\mathrm{MP}$ & $\mathrm{G}$ & $\mathrm{VG}$ \\
$C_{4}$ & $\mathrm{VG}$ & $\mathrm{MG}$ & $\mathrm{MG}$ & $\mathrm{MP}$ \\
$C_{5}$ & $\mathrm{~F}$ & $\mathrm{~F}$ & $\mathrm{MP}$ & $\mathrm{MG}$ \\
$C_{6}$ & $\mathrm{~F}$ & $\mathrm{MP}$ & $\mathrm{F}$ & $\mathrm{VG}$ \\
$C_{7}$ & $\mathrm{MG}$ & $\mathrm{MG}$ & $\mathrm{G}$ & $\mathrm{VG}$ \\
$C_{8}$ & $\mathrm{VG}$ & $\mathrm{MP}$ & $\mathrm{F}$ & $\mathrm{P}$ \\
$C_{9}$ & $\mathrm{VG}$ & $\mathrm{F}$ & $\mathrm{G}$ & $\mathrm{P}$ \\
$C_{10}$ & $\mathrm{G}$ & $\mathrm{F}$ & $\mathrm{G}$ & $\mathrm{P}$ \\
\hline
\end{tabular}

Step 1: Determine the weights of attributes in each DM's individual IVPF decision matrices. We utilize Model $\left(M \_2\right)$ and Eq. (24) to obtain the attribute weighting vector $w^{k}=\left(w_{1}^{k}, w_{2}^{k}, \cdots, w_{10}^{k}\right)$, $(k=1,2,3)$ when $\phi=0.5$.

$$
\begin{aligned}
w^{1}= & (0.090226,0.039244,0.11848,0.104194, \\
& 0.089678,0.122216,0.056471,0.138709, \\
& 0.101163,0.13962), \\
w^{2}= & (0.06314,0.041402,0.06444,0.132402, \\
& 0.085681,0.104687,0.078265,0.150843, \\
& 0.132474,0.146667),
\end{aligned}
$$


Table 6. Weighted individual Interval-Valued Pythagorean Fuzzy (IVPF) decision matrix for $E_{1}$.

\begin{tabular}{|c|c|c|c|c|}
\hline Criteria & $A_{1}$ & $A_{2}$ & $A_{3}$ & $A_{4}$ \\
\hline$C_{1}$ & $\begin{array}{l}([0.242785,0.296747], \\
[0.864838,0.897063])\end{array}$ & $\begin{array}{l}([0.160070,0.198663], \\
[0.920652,0.939376])\end{array}$ & $\begin{array}{c}([0.296747,0.373035], \\
[0.812408,0.864838])\end{array}$ & $\begin{array}{l}([0.296747,0.373035], \\
[0.812408,0.864838])\end{array}$ \\
\hline$C_{2}$ & $\begin{array}{l}([0.105954,0.131763] \\
[0.964680,0.973165])\end{array}$ & $\begin{array}{l}([0.131763,0.161489], \\
[0.953850,0.964680])\end{array}$ & $\begin{array}{l}([0.131763,0.161489], \\
[0.953850,0.964680])\end{array}$ & $\begin{array}{c}([0.105954,0.131763], \\
[0.964680,0.973165])\end{array}$ \\
\hline$C_{3}$ & $\begin{array}{l}([0.276909,0.337649], \\
[0.826391,0.867060])\end{array}$ & $\begin{array}{c}([0.105412,0.142988], \\
[0.941272,0.958621])\end{array}$ & $\begin{array}{c}([0.105412,0.142988], \\
[0.941272,0.958621])\end{array}$ & $\begin{array}{c}([0.337649,0.422630], \\
[0.761236,0.826391])\end{array}$ \\
\hline$C_{4}$ & $\begin{array}{l}([0.317773,0.398615] \\
[0.786695,0.845613])\end{array}$ & $\begin{array}{l}([0.260295,0.317773], \\
[0.845613,0.882103])\end{array}$ & $\begin{array}{l}([0.260295,0.317773], \\
[0.845613,0.882103])\end{array}$ & $\begin{array}{l}([0.098886,0.134173], \\
[0.948167,0.963519])\end{array}$ \\
\hline$C_{5}$ & $\begin{array}{l}([0.091771,0.124555] \\
[0.955224,0.968520])\end{array}$ & $\begin{array}{l}([0.091771,0.124555], \\
[0.955224,0.968520])\end{array}$ & $\begin{array}{c}([0.198070,0.242068], \\
[0.897655,0.921115])\end{array}$ & $\begin{array}{c}([0.242068,0.295884], \\
[0.865602,0.897655])\end{array}$ \\
\hline$C_{6}$ & $\begin{array}{l}([0.107052,0.145201] \\
[0.939478,0.957345])\end{array}$ & $\begin{array}{c}([0.070545,0.107052] \\
[0.957345,0.973097])\end{array}$ & $\begin{array}{c}([0.185872,0.230396], \\
[0.894058,0.918775])\end{array}$ & $\begin{array}{l}([0.342609,0.428597], \\
[0.754717,0.821438])\end{array}$ \\
\hline$C_{7}$ & $\begin{array}{l}([0.193159,0.236771] \\
[0.913122,0.934271])\end{array}$ & $\begin{array}{l}([0.193159,0.236771], \\
[0.913122,0.934271])\end{array}$ & $\begin{array}{c}([0.193159,0.236771], \\
[0.913122,0.934271])\end{array}$ & $\begin{array}{c}([0.236771,0.299198], \\
[0.878070,0.913122])\end{array}$ \\
\hline$C_{8}$ & $\begin{array}{l}([0.363495,0.453598] \\
[0.726593,0.799920])\end{array}$ & $\begin{array}{c}([0.114002,0.154578], \\
[0.931596,0.951730])\end{array}$ & $\begin{array}{c}([0.197784,0.245004], \\
[0.880648,0.908332])\end{array}$ & $\begin{array}{c}([0.037324,0.075142], \\
[0.969522,0.985492])\end{array}$ \\
\hline$C_{9}$ & $\begin{array}{l}([0.256612,0.313356] \\
[0.849748,0.885327])\end{array}$ & $\begin{array}{l}([0.097444,0.132225] \\
[0.949636,0.964561])\end{array}$ & $\begin{array}{l}([0.169362,0.210104], \\
[0.911472,0.932281])\end{array}$ & $\begin{array}{c}([0.064196,0.097444], \\
[0.964561,0.977679])\end{array}$ \\
\hline$C_{10}$ & $\begin{array}{l}([0.364604,0.454920] \\
[0.725070,0.798748])\end{array}$ & $\begin{array}{c}([0.198419,0.245782], \\
[0.879913,0.907758])\end{array}$ & $\begin{array}{c}([0.299547,0.364604], \\
[0.798748,0.845270])\end{array}$ & $\begin{array}{c}([0.037447,0.075388], \\
[0.969325,0.985397])\end{array}$ \\
\hline
\end{tabular}

$w^{3}=(0.090811,0.043818,0.132289,0.110908$

$0.043818,0.109068,0.081381,0.13646$

$0.137477,0.113971)$.

Step 2: Calculate the weighted individual IVPF decision matrices $\mathscr{P}^{k}$, as depicted in Tables 6-8.

Step 3: Obtain weights of the decision-makers. In this step, the algorithm proposed in Subsection 4.1 is applied to compute the weighting vector of experts.
When $v=0.5$, they are computed by:

$$
\lambda=(0.378939,0.188696,0.432365) \text {. }
$$

Step 4: Construct the overall group IVPF decision matrix. We aggregate the weighted IVPF decision matrices $\Psi^{k}$ to determine the overall group decision matrix $\Psi$, as shown in Table 9 .

Step 5: Compute the normalized IVPF overallperformance decision matrix. Since all the attributes, except for $C_{2}$, are of benefit type, their rating values do not require normalization. The results of 
Table 7. Weighted individual Interval-Valued Pythagorean Fuzzy (IVPF) decision matrix for $E_{2}$.

\begin{tabular}{|c|c|c|c|c|}
\hline Criteria & $A_{1}$ & $A_{2}$ & $A_{3}$ & $A_{4}$ \\
\hline$C_{1}$ & $\begin{array}{c}([0.249941,0.315513] \\
[0.864689,0.903373])\end{array}$ & $\begin{array}{l}([0.204020,0.249941] \\
[0.903373,0.926799])\end{array}$ & $\begin{array}{c}([0.204020,0.249941] \\
[0.903373,0.926799])\end{array}$ & $\begin{array}{c}([0.204020,0.249941], \\
[0.903373,0.926799])\end{array}$ \\
\hline$C_{2}$ & $\begin{array}{c}([0.135305,0.165809] \\
[0.951375,0.962774])\end{array}$ & $\begin{array}{c}([0.108811,0.135305] \\
[0.962774,0.971710])\end{array}$ & $\begin{array}{c}([0.135305,0.165809] \\
[0.951375,0.962774])\end{array}$ & $\begin{array}{c}([0.135305,0.165809], \\
[0.951375,0.962774])\end{array}$ \\
\hline$C_{3}$ & $\begin{array}{c}([0.168372,0.206064] \\
[0.925349,0.942664])\end{array}$ & $\begin{array}{c}([0.135526,0.168372] \\
[0.942664,0.956317])\end{array}$ & $\begin{array}{c}([0.135526,0.168372], \\
[0.942664,0.956317])\end{array}$ & $\begin{array}{l}([0.206064,0.252418], \\
[0.901485,0.925349])\end{array}$ \\
\hline$C_{4}$ & $\begin{array}{c}([0.355695,0.444284] \\
[0.737222,0.808081])\end{array}$ & $\begin{array}{c}([0.193322,0.239536] \\
[0.885752,0.912311])\end{array}$ & $\begin{array}{c}([0.239536,0.292051] \\
[0.852648,0.885752])\end{array}$ & $\begin{array}{c}([0.073419,0.111397], \\
[0.953873,0.970888])\end{array}$ \\
\hline$C_{5}$ & $\begin{array}{l}([0.156037,0.193692] \\
[0.924494,0.942339])\end{array}$ & $\begin{array}{c}([0.089711,0.121769], \\
[0.957176,0.969902])\end{array}$ & $\begin{array}{c}([0.156037,0.193692] \\
[0.924494,0.942339])\end{array}$ & $\begin{array}{c}([0.236771,0.289507] \\
[0.871187,0.901985])\end{array}$ \\
\hline$C_{6}$ & $\begin{array}{l}([0.099119,0.134488] \\
[0.947928,0.963349])\end{array}$ & $\begin{array}{c}([0.065302,0.099119], \\
[0.963349,0.976911])\end{array}$ & $\begin{array}{c}([0.099119,0.134488] \\
[0.947928,0.963349])\end{array}$ & $\begin{array}{c}([0.260889,0.318484], \\
[0.844943,0.881580])\end{array}$ \\
\hline$C_{7}$ & $\begin{array}{l}([0.226572,0.277211] \\
[0.881648,0.910075])\end{array}$ & $\begin{array}{c}([0.185272,0.226572] \\
[0.910075,0.930798])\end{array}$ & $\begin{array}{c}([0.277211,0.349119], \\
[0.835094,0.881648])\end{array}$ & $\begin{array}{l}([0.226572,0.277211], \\
[0.881648,0.910075])\end{array}$ \\
\hline$C_{8}$ & $\begin{array}{c}([0.377917,0.470740] \\
[0.706573,0.784450])\end{array}$ & $\begin{array}{c}([0.206075,0.255154] \\
[0.870910,0.900724])\end{array}$ & $\begin{array}{c}([0.255154,0.310776] \\
[0.833926,0.870910])\end{array}$ & $\begin{array}{c}([0.038921,0.078350], \\
[0.966901,0.984233])\end{array}$ \\
\hline$C_{9}$ & $\begin{array}{c}([0.355785,0.444392] \\
[0.737100,0.807988])\end{array}$ & $\begin{array}{c}([0.111427,0.151104], \\
[0.934568,0.953849])\end{array}$ & $\begin{array}{c}([0.292126,0.355785] \\
[0.807988,0.852574])\end{array}$ & $\begin{array}{l}([0.111427,0.151104], \\
[0.934568,0.953849])\end{array}$ \\
\hline$C_{10}$ & $\begin{array}{c}([0.373036,0.464950], \\
[0.713401,0.789741])\end{array}$ & $\begin{array}{c}([0.251713,0.306655] \\
[0.838130,0.874250])\end{array}$ & $\begin{array}{c}([0.251713,0.306655] \\
[0.838130,0.874250])\end{array}$ & $\begin{array}{c}([0.038379,0.077261] \\
[0.967802,0.984666])\end{array}$ \\
\hline
\end{tabular}

normalizing the IVPF overall performance decision matrix for $C_{2}$ are shown in Table 10 .

Step 6: Compute values $S_{i}$ and $R_{i}$, as presented in Table 11.

Step 7: Defuzzify the values of $\tilde{S}_{i}$ and $\tilde{R}_{i}$, as given in Table 12.

Step 8: Compute the values $Q_{i}$, as displayed in Table 13 .

Step 9: Rank the alternatives by sorting the values $Q_{i}$ in descending order.

$$
A_{1} \succ A_{4} \succ A_{2} \succ A_{3} .
$$

To test the robustness of the model, parameters $\phi$ and $v$ may vary. As shown in Table 14 , the ranking remains intact. The results show that project $A_{1}$ has the best ranking. Then, projects $A_{4}, A_{2}$, and $A_{3}$ have the best outcomes, respectively.

Another sensitivity analysis is done to represent the impact of the weights of the experts and attributes on the ranking of the alternatives. In this case, the weights of the DMs and attributes are changed to represent if different weights can affect the final results or not. The analysis indicates that changing the weights leads to different ranking results. On the other hand, it is shown that the proposed method is more 
Table 8. Weighted individual Interval-Valued Pythagorean Fuzzy (IVPF) decision matrix for $E_{3}$.

\begin{tabular}{|c|c|c|c|c|}
\hline Criteria & $A_{1}$ & $A_{2}$ & $A_{3}$ & $A_{4}$ \\
\hline$C_{1}$ & $\begin{array}{l}([0.243547,0.297663], \\
[0.864024,0.896431])\end{array}$ & $\begin{array}{l}([0.160581,0.199293], \\
[0.920159,0.938995])\end{array}$ & $\begin{array}{c}([0.243547,0.297663] \\
[0.864024,0.896431])\end{array}$ & $\begin{array}{c}([0.297663,0.374154], \\
[0.811314,0.864024])\end{array}$ \\
\hline$C_{2}$ & $\begin{array}{l}([0.111922,0.139159], \\
[0.960646,0.970084])\end{array}$ & $\begin{array}{l}([0.111922,0.139159], \\
[0.960646,0.970084])\end{array}$ & $\begin{array}{c}([0.139159,0.170509] \\
[0.948612,0.960646])\end{array}$ & $\begin{array}{c}([0.139159,0.170509] \\
[0.948612,0.960646])\end{array}$ \\
\hline$C_{3}$ & $\begin{array}{l}([0.111350,0.151000], \\
[0.934656,0.953912])\end{array}$ & $\begin{array}{l}([0.111350,0.151000], \\
[0.934656,0.953912])\end{array}$ & $\begin{array}{c}([0.291932,0.355553] \\
[0.808228,0.852764])\end{array}$ & $\begin{array}{c}([0.355553,0.444114] \\
[0.737413,0.808228])\end{array}$ \\
\hline$C_{4}$ & $\begin{array}{l}([0.327301,0.410148], \\
[0.774625,0.836524])\end{array}$ & $\begin{array}{l}([0.219754,0.268252], \\
[0.875001,0.903369])\end{array}$ & $\begin{array}{c}([0.219754,0.268252] \\
[0.875001,0.903369])\end{array}$ & $\begin{array}{c}([0.102006,0.138389] \\
[0.944920,0.961214])\end{array}$ \\
\hline$C_{5}$ & $\begin{array}{l}([0.111922,0.139159] \\
[0.960646,0.970084])\end{array}$ & $\begin{array}{l}([0.111922,0.139159], \\
[0.960646,0.970084])\end{array}$ & $\begin{array}{c}([0.139159,0.170509] \\
[0.948612,0.960646])\end{array}$ & $\begin{array}{c}([0.139159,0.170509] \\
[0.948612,0.960646])\end{array}$ \\
\hline$C_{6}$ & $\begin{array}{l}([0.175755,0.217968], \\
[0.904894,0.927187])\end{array}$ & $\begin{array}{l}([0.101161,0.137247], \\
[0.945809,0.961845])\end{array}$ & $\begin{array}{c}([0.175755,0.217968] \\
[0.904894,0.927187])\end{array}$ & $\begin{array}{c}([0.324724,0.407032] \\
[0.777915,0.839006])\end{array}$ \\
\hline$C_{7}$ & $\begin{array}{c}([0.188858,0.230918], \\
[0.906667,0.928144])\end{array}$ & $\begin{array}{c}([0.188858,0.230918], \\
[0.906667,0.928144])\end{array}$ & $\begin{array}{c}([0.230918,0.282454] \\
[0.877238,0.906667])\end{array}$ & $\begin{array}{c}([0.282454,0.355551] \\
[0.829124,0.877238])\end{array}$ \\
\hline$C_{8}$ & $\begin{array}{l}([0.360739,0.450309], \\
[0.730366,0.802821])\end{array}$ & $\begin{array}{l}([0.113080,0.153334], \\
[0.932667,0.952494])\end{array}$ & $\begin{array}{c}([0.196205,0.243070] \\
[0.882464,0.909749])\end{array}$ & $\begin{array}{c}([0.074532,0.113080] \\
[0.952494,0.970009])\end{array}$ \\
\hline$C_{9}$ & $\begin{array}{l}([0.361989,0.451801], \\
[0.728657,0.801508])\end{array}$ & $\begin{array}{l}([0.196921,0.243947], \\
[0.881642,0.909108])\end{array}$ & $\begin{array}{c}([0.297345,0.361989] \\
[0.801508,0.847454])\end{array}$ & $\begin{array}{c}([0.074809,0.113498], \\
[0.952148,0.969789])\end{array}$ \\
\hline$C_{10}$ & $\begin{array}{c}([0.271792,0.331535], \\
[0.832411,0.871780])\end{array}$ & $\begin{array}{l}([0.179599,0.222692], \\
[0.900837,0.924041])\end{array}$ & $\begin{array}{c}([0.271792,0.331535] \\
[0.832411,0.871780])\end{array}$ & $\begin{array}{c}([0.068130,0.103398], \\
[0.960165,0.974889])\end{array}$ \\
\hline
\end{tabular}

sensitive to the experts' weights than the weights of attributes. The computational results of the second sensitivity analysis are reported in Table 15.

In order to validate the obtained results, the decision method of Ashtiani et al. [38] is utilized to evaluate the alternatives. The results are presented in Table 16. It can be observed that the best and worst alternatives remain the same. However, the presented method enjoys several more advantages than the method proposed by Ashtiani et al. [38], for instance:

1. The developed method applies IVPFS, one of the most powerful tools in dealing with uncertainty, to 
Table 9. Interval-Valued Pythagorean Fuzzy (IVPF) overall performance decision matrix.

\begin{tabular}{|c|c|c|c|c|}
\hline Criteria & $A_{1}$ & $A_{2}$ & $A_{3}$ & $A_{4}$ \\
\hline$C_{1}$ & $\begin{array}{l}([0.244481,0.300787], \\
[0.864458,0.897976])\end{array}$ & $\begin{array}{c}([0.169508,0.209662], \\
[0.917154,0.936825])\end{array}$ & $\begin{array}{c}([0.258917,0.321449], \\
[0.851213,0.889902])\end{array}$ & $\begin{array}{c}([0.282330,0.354329] \\
[0.828359,0.875847])\end{array}$ \\
\hline$C_{2}$ & $\begin{array}{l}([0.114577,0.141938], \\
[0.960413,0.969865])\end{array}$ & $\begin{array}{c}([0.119299,0.147362] \\
[0.958465,0.968339])\end{array}$ & $\begin{array}{c}([0.135672,0.166256] \\
[0.951116,0.962574])\end{array}$ & $\begin{array}{c}([0.126842,0.156053], \\
[0.955193,0.965774])\end{array}$ \\
\hline$C_{3}$ & $\begin{array}{c}([0.200551,0.249043] \\
[0.890372,0.917964])\end{array}$ & $\begin{array}{l}([0.114197,0.151524], \\
[0.938668,0.956148])\end{array}$ & $\begin{array}{c}([0.212586,0.263022], \\
[0.881499,0.910915])\end{array}$ & $\begin{array}{c}([0.326183,0.407893] \\
[0.775188,0.836145])\end{array}$ \\
\hline$C_{4}$ & $\begin{array}{l}([0.329398,0.412682] \\
[0.771934,0.834492])\end{array}$ & $\begin{array}{l}([0.231688,0.283484], \\
[0.865739,0.896916])\end{array}$ & $\begin{array}{c}([0.239628,0.292516], \\
[0.859539,0.891930])\end{array}$ & $\begin{array}{c}([0.096038,0.132087], \\
[0.947834,0.963906])\end{array}$ \\
\hline$C_{5}$ & $\begin{array}{l}([0.114970,0.146164], \\
[0.951674,0.964198])\end{array}$ & $\begin{array}{l}([0.100639,0.130583], \\
[0.957933,0.969457])\end{array}$ & $\begin{array}{l}([0.166962,0.204814], \\
[0.924467,0.942044])\end{array}$ & $\begin{array}{c}([0.203333,0.248974], \\
[0.901655,0.925206])\end{array}$ \\
\hline$C_{6}$ & $\begin{array}{l}([0.140008,0.178997] \\
[0.925929,0.945302])\end{array}$ & $\begin{array}{l}([0.084374,0.119787], \\
[0.953464,0.968931])\end{array}$ & $\begin{array}{c}([0.168354,0.210128], \\
[0.908704,0.930686])\end{array}$ & $\begin{array}{c}([0.321069,0.401107], \\
[0.781130,0.840115])\end{array}$ \\
\hline$C_{7}$ & $\begin{array}{c}([0.198153,0.242571] \\
[0.904320,0.927015])\end{array}$ & $\begin{array}{l}([0.189835,0.232351], \\
[0.909751,0.930962])\end{array}$ & $\begin{array}{c}([0.227595,0.281137], \\
[0.882430,0.912200])\end{array}$ & $\begin{array}{l}([0.255949,0.321440], \\
[0.857220,0.896864])\end{array}$ \\
\hline$C_{8}$ & $\begin{array}{l}([0.365097,0.455507], \\
[0.724393,0.798226])\end{array}$ & $\begin{array}{l}([0.136147,0.177884], \\
[0.920287,0.942216])\end{array}$ & $\begin{array}{l}([0.209306,0.258130], \\
[0.872412,0.901757])\end{array}$ & $\begin{array}{l}([0.056724,0.093983], \\
[0.961631,0.978531])\end{array}$ \\
\hline$C_{9}$ & $\begin{array}{l}([0.325616,0.405244] \\
[0.774048,0.833559])\end{array}$ & $\begin{array}{l}([0.151025,0.192022], \\
[0.916846,0.938202])\end{array}$ & $\begin{array}{c}([0.256185,0.313385] \\
[0.842802,0.879649])\end{array}$ & $\begin{array}{c}([0.079554,0.116137], \\
[0.953474,0.969734])\end{array}$ \\
\hline$C_{10}$ & $\begin{array}{c}([0.330283,0.410129], \\
[0.767316,0.827769])\end{array}$ & $\begin{array}{c}([0.202209,0.249437], \\
[0.880777,0.908294])\end{array}$ & $\begin{array}{c}([0.279196,0.340242], \\
[0.820550,0.862098])\end{array}$ & $\begin{array}{c}([0.053080,0.088913], \\
[0.965067,0.980703])\end{array}$ \\
\hline
\end{tabular}

Table 10. Normalized Interval-Valued Pythagorean Fuzzy (IVPF) overall performance decision matrix for $C_{2}$.

\begin{tabular}{ccccc}
\hline Criteria & $\boldsymbol{A}_{\mathbf{1}}$ & $\boldsymbol{A}_{\mathbf{2}}$ & $\boldsymbol{A}_{\mathbf{3}}$ & $\boldsymbol{A}_{\mathbf{4}}$ \\
\hline \multirow{2}{*}{$C_{2}$} & $([0.960413,0.969865]$, & $([0.958465,0.968339]$, & $([0.951116,0.962574]$, & $([0.955193,0.965774]$, \\
& $[0.114577,0.141938])$ & $[0.119299,0.147362])$ & $[0.135672,0.166256])$ & $[0.126842,0.156053])$ \\
\hline
\end{tabular}

Table 11. Values of $S_{i}$ and $R_{i}$.

\begin{tabular}{ccccc}
\hline & $\boldsymbol{i}=\mathbf{1}$ & $\boldsymbol{i}=\mathbf{2}$ & $\boldsymbol{i}=\mathbf{3}$ & $\boldsymbol{i}=\mathbf{4}$ \\
\hline \multirow{2}{*}{$\boldsymbol{S}_{\boldsymbol{i}}$} & $([0.979767,0.989627]$, & $([0.967312,0.978307]$, & $([0.970006,0.982249]$, & $([0.971263,0.983365]$, \\
& $[0.023340,0.045437])$ & $[0.054907,0.083128])$ & $[0.039135,0.065743])$ & $[0.041243,0.071463])$ \\
& & & & \\
\multirow{2}{*}{$\boldsymbol{R}_{\boldsymbol{i}}$} & $([0.960413,0.969865]$, & $([0.958465,0.968339]$, & $([0.951116,0.962574]$, & $([0.955193,0.965774]$, \\
& $[0.114577,0.141938])$ & $[0.119299,0.147362])$ & $[0.135672,0.166256])$ & $[0.126842,0.156053])$ \\
\hline
\end{tabular}


Table 12. Crisp values of $S_{i}$ and $R_{i}$.

\begin{tabular}{ccccc}
\hline & $\boldsymbol{i}=\mathbf{1}$ & $\boldsymbol{i}=\mathbf{2}$ & $\boldsymbol{i}=\mathbf{3}$ & $\boldsymbol{i}=\mathbf{4}$ \\
\hline $\boldsymbol{S}_{\boldsymbol{i}}$ & 0.80212 & 0.727728 & 0.745064 & 0.75448 \\
$\boldsymbol{R}_{\boldsymbol{i}}$ & 0.70554 & 0.697885 & 0.66985 & 0.685247 \\
\hline
\end{tabular}

Table 13. Values of $Q_{i}$.

\begin{tabular}{ccccc}
\hline & $\boldsymbol{i}=\mathbf{1}$ & $\boldsymbol{i}=\mathbf{2}$ & $\boldsymbol{i}=\mathbf{3}$ & $\boldsymbol{i}=\mathbf{4}$ \\
\hline $\boldsymbol{Q}_{\boldsymbol{i}}$ & 1 & 0.254676 & 0.157481 & 0.382896 \\
\hline
\end{tabular}

Table 14. Final results of the proposed method with different values of $\phi$ and $v$.

\begin{tabular}{|c|c|c|}
\hline$\phi$ and $v$ values & Alternatives & Ranking \\
\hline \multirow{4}{*}{$\phi=.1$ and $v=.1$} & $A_{1}$ & 1 \\
\hline & $A_{2}$ & 3 \\
\hline & $A_{3}$ & 4 \\
\hline & $A_{4}$ & 2 \\
\hline \multirow{4}{*}{$\phi=.3$ and $v=.3$} & $A_{1}$ & 1 \\
\hline & $A_{2}$ & 3 \\
\hline & $A_{3}$ & 4 \\
\hline & $A_{4}$ & 2 \\
\hline \multirow{4}{*}{$\phi=.5$ and $v=.5$} & $A_{1}$ & 1 \\
\hline & $A_{2}$ & 3 \\
\hline & $A_{3}$ & 4 \\
\hline & $A_{4}$ & 2 \\
\hline \multirow{4}{*}{$\phi=.7$. and $v=.7$} & $A_{1}$ & 1 \\
\hline & $A_{2}$ & 3 \\
\hline & $A_{3}$ & 4 \\
\hline & $A_{4}$ & 2 \\
\hline \multirow{4}{*}{$\phi=.9$ and $v=.9$} & $A_{1}$ & 1 \\
\hline & $A_{2}$ & 3 \\
\hline & $A_{3}$ & 4 \\
\hline & $A_{4}$ & 2 \\
\hline
\end{tabular}

increase the flexibility and ability of expressing and calculating the uncertainty in the decision problem;

2. DMs are given a weight objectively based on the compromise solution method;
3. The method uses an optimization model that simultaneously considers the deviation between attribute assessments and knowledge measure to address the weights of unknown criteria.

This model utilizes all the available information on decision preferences and creates a comprehensive weighting approach.

\section{Conclusion}

In this paper, a new decision-making approach was introduced that used Interval-Valued Pythagorean Fuzzy Sets (IVPFSs) to model uncertainty in the sustainable transport investment selection problem. The model functions based on the notion of maximizing the divergence of attribute evaluation from the fuzziest number in IVPFSs and the deviation between attribute evaluations to handle the weight of criteria used in the selection process. Moreover, an extended form of the VIKOR method was introduced to determine the weight of the DMs based on positive and negative ideal solutions. To illustrate the applicability of the proposed approach, real data from an Iranian transport complex firm was applied. The results were presented, and the sensitivity analysis of the parameters of the model was carried out. For further research, extending the developed method to support a higher degree of uncertainty in modeling will be an interesting idea. For instance, the application of the interval-valued Pythagorean hesitant fuzzy set will allow incorporating additional knowledge about uncertainty in the decisionmaking process. The presented method can be improved by applying other weighting methods, which will rely upon not only the available information of decision preferences but also the judgments of the DMs. In other words, developing new approaches to aggregating the subjective and objective weights of the criteria and DMs, compared to the recent studies [3944], is another interesting research direction. 
Table 15. Computational results of the sensitivity analysis.

\begin{tabular}{|c|c|c|c|c|c|c|c|}
\hline \multirow{2}{*}{ Scenario } & \multirow{2}{*}{ Experts } & \multirow{2}{*}{$\begin{array}{l}\text { Weight of } \\
\text { each DM }\end{array}$} & \multirow{2}{*}{ Attribute weighting vector } & \multicolumn{4}{|c|}{ Alternatives } \\
\hline & & & & $\boldsymbol{A}_{1}$ & $\boldsymbol{A}_{2}$ & $\boldsymbol{A}_{\mathbf{3}}$ & $\boldsymbol{A}_{4}$ \\
\hline \multirow{3}{*}{$\begin{array}{l}\text { Scenario } 1 \\
\text { (weights of } \\
\text { DMs are } \\
\text { changed) }\end{array}$} & $E_{1}$ & 0.378939 & $\begin{aligned} w^{1}= & (0.090226,0.039244,0.11848,0.104194,0.089678 \\
& 0.122216,0.056471,0.138709,0.101163,0.13962)\end{aligned}$ & \multirow{3}{*}{1} & \multirow{3}{*}{2} & \multirow{3}{*}{4} & \multirow{3}{*}{3} \\
\hline & $E_{2}$ & 0.432365 & $\begin{aligned} w^{2}= & (0.06314,0.041402,0.06444,0.132402,0.085681 \\
& 0.104687,0.078265,0.150843,0.132474,0.146667)\end{aligned}$ & & & & \\
\hline & $E_{3}$ & 0.188696 & $\begin{aligned} w^{3}= & (0.090811,0.043818,0.132289,0.110908,0.043818 \\
& 0.109068,0.081381,0.13646,0.137477,0.113971)\end{aligned}$ & & & & \\
\hline \multirow{3}{*}{$\begin{array}{l}\text { Scenario } 2 \\
\text { (weights of } \\
\text { DMs are } \\
\text { changed) }\end{array}$} & $E_{1}$ & 0.188696 & $\begin{aligned} w^{1}= & (0.090226,0.039244,0.11848,0.104194,0.089678 \\
& 0.122216,0.056471,0.138709,0.101163,0.13962)\end{aligned}$ & \multirow{3}{*}{1} & \multirow{3}{*}{2} & \multirow{3}{*}{4} & \multirow{3}{*}{3} \\
\hline & $E_{2}$ & 0.378939 & $\begin{aligned} w^{2}= & (0.06314,0.041402,0.06444,0.132402,0.085681 \\
& 0.104687,0.078265,0.150843,0.132474,0.146667)\end{aligned}$ & & & & \\
\hline & $E_{3}$ & 0.432365 & $\begin{aligned} w^{3}= & (0.090811,0.043818,0.132289,0.110908,0.043818 \\
& 0.109068,0.081381,0.13646,0.137477,0.113971)\end{aligned}$ & & & & \\
\hline \multirow{3}{*}{$\begin{array}{l}\text { Scenario } 3 \\
\text { (weights of } \\
\text { criteria are } \\
\text { changed) }\end{array}$} & $E_{1}$ & 0.378939 & $\begin{aligned} w^{1}= & (0.11848,0.104194,0.090226,0.039244,0.089678 \\
& 0.122216,0.056471,0.138709,0.101163,0.13962)\end{aligned}$ & \multirow{3}{*}{1} & \multirow{3}{*}{3} & \multirow{3}{*}{4} & \multirow{3}{*}{2} \\
\hline & $E_{2}$ & 0.188696 & $\begin{aligned} w^{2}= & (0.06444,0.132402,0.06314,0.041402,0.085681 \\
& 0.104687,0.078265,0.150843,0.132474,0.146667)\end{aligned}$ & & & & \\
\hline & $E_{3}$ & 0.432365 & $\begin{aligned} w^{3}= & (0.132289,0.110908,0.090811,0.043818,0.043818 \\
& 0.109068,0.081381,0.13646,0.137477,0.113971)\end{aligned}$ & & & & \\
\hline \multirow{3}{*}{$\begin{array}{l}\text { Scenario } 4 \\
\text { (weights of } \\
\text { criteria are } \\
\text { changed) }\end{array}$} & $E_{1}$ & 0.378939 & $\begin{aligned} w^{1}= & (0.090226,0.039244,0.11848,0.104194,0.089678 \\
& 0.122216,0.056471,0.138709,0.101163,0.13962)\end{aligned}$ & \multirow{3}{*}{1} & \multirow{3}{*}{3} & \multirow{3}{*}{4} & \multirow{3}{*}{2} \\
\hline & $E_{2}$ & 0.188696 & $\begin{aligned} w^{2}= & (0.06314,0.041402,0.06444,0.132402,0.085681 \\
& 0.104687,0.078265,0.150843,0.132474,0.146667)\end{aligned}$ & & & & \\
\hline & $E_{3}$ & 0.432365 & $\begin{aligned} w^{3}= & (0.090811,0.043818,0.132289,0.110908,0.043818 \\
& 0.109068,0.081381,0.13646,0.137477,0.113971)\end{aligned}$ & & & & \\
\hline
\end{tabular}

Table 16. Results of the ranking method of Ashtiani et al. [38].

\begin{tabular}{ccccc}
\hline Alternatives & $\boldsymbol{R} \boldsymbol{C}_{\mathbf{1}}$ & $\boldsymbol{R} \boldsymbol{C}_{\boldsymbol{2}}$ & $\boldsymbol{R} \boldsymbol{C}_{\boldsymbol{i}}^{*}$ & Ranking \\
\hline$A_{1}$ & 0.44 & 0.44 & 0.44 & 1 \\
$A_{2}$ & 0.39 & 0.4 & 0.4 & 2 \\
$A_{3}$ & 0.32 & 0.33 & 0.33 & 4 \\
$A_{4}$ & 0.31 & 0.33 & 0.32 & 3 \\
\hline
\end{tabular}

\section{References}

1. Rassafi, A.A. and Vaziri, M. "Sustainable transport indicators: definition and integration", International Journal of Environmental Science \& Technology, 2, pp. 83-96 (2005).

2. Awasthi, A., Chauhan, S.S., and Omrani, H. "Application of fuzzy TOPSIS in evaluating sustainable transportation systems", Expert Systems with Applications, 38, pp. 12270-12280 (2011).
3. Shiau, T.A. "Evaluating transport infrastructure decisions under uncertainty", Transportation Planning and Technology, 37, pp. 525-538 (2014).

4. Halouani, N., Chabchoub, H., and Martel, J.M. "PROMETHEE-MD-2T method for project selection", European Journal of Operational Research, 195, pp. 841-849 (2009).

5. Awasthi, A. and Chauhan, S.S. "A hybrid approach integrating Affinity Diagram, AHP and fuzzy TOPSIS for sustainable city logistics planning", Applied Mathematical Modelling, 36, pp. 573-584 (2012).

6. Mandic, D., Jovanovic, P., and Bugarinovic, M. "Twophase model for multi-criteria project ranking: Serbian railways case study", Transport Policy, 36, pp. 88-104 (2014).

7. Liu, K., Zhang, J., Yan, X., Liu, Y., Zhang, D., and $\mathrm{Hu}, \mathrm{W}$. "Safety assessment for inland waterway transportation with an extended fuzzy TOPSIS", Proceedings of the Institution of Mechanical Engineers, 
Part O: Journal of Risk and Reliability, 230, pp. 323333 (2016).

8. Gul, M., Guneri, A.F., and Nasirli, S.M. "A fuzzybased model for risk assessment of routes in oil transportation", International Journal of Environmental Science and Technology, pp. 1-16 (2018).

9. Kundu, P., Kar, S., and Maiti, M. "A fuzzy MCDM method and an application to solid transportation problem with mode preference", Soft Computing, 18(9), pp. 1853-1864 (2014).

10. Pamučar, D. and Ćirović, G. "The selection of transport and handling resources in logistics centers using Multi-Attributive Border Approximation area Comparison (MABAC)", Expert Systems with Applications, 42(6), pp. 3016-3028 (2015).

11. Essaadi, I., Grabot, B., and Féniès, P. "Location of global logistic hubs within Africa based on a fuzzy multi-criteria approach", Computers \& Industrial Engineering, 132, pp. 1-22 (2019).

12. Deng, X., Wei, G., Gao, H., and Wang, J. "Models for safety assessment of construction project with some 2-tuple linguistic Pythagorean fuzzy Bonferroni mean operators", IEEE Access, 6, pp. 52105-52137 (2018).

13. Mohagheghi, V., Mousavi, S.M., and Vahdani, B. "Enhancing decision-making flexibility by introducing a new last aggregation evaluating approach based on multi-criteria group decision making and Pythagorean fuzzy sets", Applied Soft Computing, 61, pp. 527-535 (2017).

14. Gitinavard, H., Mousavi, S.M., and Vahdani, B. "A new multi-criteria weighting and ranking model for group decision-making analysis based on intervalvalued hesitant fuzzy sets to selection problems", Neural Computing and Applications, 27(6), pp. 15931605 (2016).

15. Samanta, S. and Jana, D.K. "A multi-item transportation problem with mode of transportation preference by MCDM method in interval type-2 fuzzy environment", Neural Computing and Applications, 31(2), pp. 605-617 (2019).

16. Mohagheghi, V., Mousavi, S.M., Aghamohagheghi, M., and Vahdani, B. "A new approach of multi-criteria analysis for the evaluation and selection of sustainable transport investment projects under uncertainty: A case study", International Journal of Computational Intelligence Systems, 10(1), pp. 605-626 (2017).

17. Zhang, X. "Multicriteria Pythagorean fuzzy decision analysis: a hierarchical QUALIFLEX approach with the closeness index-based ranking methods", Information Sciences, 330, pp. 104-124 (2016).

18. Foroozesh, N., Tavakkoli-Moghaddam, R., Mousavi, S.M., and Vahdani, B. "A new comprehensive possibilistic group decision approach for resilient supplier selection with mean-variance-skewness-kurtosis and asymmetric information under interval-valued fuzzy uncertainty", Neural Computing and Applications, 31(11), pp. 6959-6979 (2019).
19. Ma, J., Fan, Z.P., and Huang, L.H. "A subjective and objective integrated approach to determine attribute weights", European Journal of Operational Research, 112, pp. 397-404 (1999).

20. Mousavi, S.M., Vahdani, B., Tavakkoli-Moghaddam, R., and Tajik, N. "Soft computing based on a fuzzy grey group compromise solution approach with an application to the selection problem of material handling equipment", International Journal of Computer Integrated Manufacturing, 27(6), pp. 547-569 (2014).

21. Wang, Z.J. and Li, K.W. "An interval-valued intuitionistic fuzzy multiattribute group decision making framework with incomplete preference over alternatives", Expert Systems with Applications, 39, pp. 13509-13516 (2012).

22. Chen, T.Y., Wang, H.P., and Lu, Y.Y. "A multicriteria group decision-making approach based on intervalvalued intuitionistic fuzzy sets: A comparative perspective", Expert Systems with Applications, 38, pp. 7647-7658 (2011).

23. Vahdani, B., Mousavi, S.M., Tavakkoli-Moghaddam, R., Ghodratnama, A., and Mohammadi, M. "Robot selection by a multiple criteria complex proportional assessment method under an interval-valued fuzzy environment", The International Journal of $A d$ vanced Manufacturing Technology, 73(5-8), pp. 687697 (2014).

24. $\mathrm{Xu}, \mathrm{Z}$. "A deviation-based approach to intuitionistic fuzzy multiple attribute group decision making", Group Decision and Negotiation, 19, pp. 57-76 (2010).

25. Hung, W.L. and Yang, M.S. "Fuzzy entropy on intuitionistic fuzzy sets", International Journal of Intelligent Systems, 21, pp. 443-451 (2006).

26. Vlachos, I.K. and Sergiadis, G.D. "Intuitionistic fuzzy information-applications to pattern recognition", Pattern Recognition Letters, 28, pp. 197-206 (2007).

27. Yue, Z. "A method for group decision-making based on determining weights of decision makers using TOPSIS", Applied Mathematical Modelling, 35, pp. 19261936 (2011).

28. Qi, X., Liang, C., and Zhang, J. "Generalized crossentropy based group decision making with unknown expert and attribute weights under interval-valued intuitionistic fuzzy environment", Computers \& Industrial Engineering, 79, pp. 52-64 (2015).

29. Opricovic, S. "Multicriteria optimization of civil engineering systems", Faculty of Civil Engineering, Belgrade, 2, pp. 5-21 (1998).

30. Peng, X. and Yang, Y. "Fundamental properties of interval-valued pythagorean fuzzy aggregation operators", International Journal of Intelligent Systems, $\mathbf{3 1}$, pp. 444-487 (2015).

31. Garg, H. "A novel accuracy function under intervalvalued Pythagorean fuzzy environment for solving multicriteria decision making problem", Journal of Intelligent \& Fuzzy Systems, 31, pp. 1-12 (2016). 
32. Liang, W., Zhang, X., and Liu, M. "The maximizing deviation method based on interval-valued pythagorean fuzzy weighted aggregating operator for multiple criteria group decision analysis", Discrete Dynamics in Nature and Society, 2015, Article ID 746572, pp. 1-15 (2015).

33. Szmidt, E. and Kacprzyk, J. "Entropy for intuitionistic fuzzy sets", Fuzzy Sets and Systems, 118, pp. 467-477 (2001).

34. Szmidt, E., Kacprzyk, J., and Bujnowski, P. "How to measure the amount of knowledge conveyed by Atanassov's intuitionistic fuzzy sets", Information Sciences, 257, pp. 276-285 (2014).

35. Kim, S.H. and Ahn, B.S. "Interactive group decision making procedure under incomplete information", European Journal of Operational Research, 116, pp. 498507 (1999).

36. Salling, K.B. and Pryn, M.R. "Sustainable transport project evaluation and decision support: indicators and planning criteria for sustainable development", International Journal of Sustainable Development \& World Ecology, 22, pp. 346-357 (2015).

37. Véron-Okamoto, A. and Sakamoto, K., Toward a Sustainability Appraisal Framework for Transport, ADB Sustainable Development Working Paper Series, Asian Development Bank, Manila, Philippines (2014).

38. Ashtiani, B., Haghighirad, F., Makui, A., and Ali Montazer, G. "Extension of fuzzy TOPSIS method based on interval-valued fuzzy sets", Applied Soft Computing, 9(2), pp. 457-461 (2009).

39. Gitinavard, H., Mousavi, S.M., and Vahdani, B. "Soft computing based on hierarchical evaluation approach and criteria interdependencies for energy decisionmaking problems: A case study", Energy, 118, pp. 556-577 (2017).

40. Mousavi, M., Gitinavard, H., and Mousavi, S.M. "A soft computing based-modified ELECTRE model for renewable energy policy selection with unknown information", Renewable and Sustainable Energy Reviews, 68(1), pp. 774-787 (2017).

41. Vahdani, B., Salimi, M., and Mousavi, S.M. "A new compromise solution model based on Dantzig-wolf decomposition for solving belief multi-objective nonlinear programming problems with block angular structure", International Journal of Information Technology \& Decision Making, 16(2), pp. 333-387 (2017).

42. Dorfeshan, Y., Mousavi, S.M., Mohagheghi, V., and Vahdani, B. "Selecting project-critical path by a new interval type-2 fuzzy decision methodology based on MULTIMOORA, MOOSRA and TPOP methods", Computers \& Industrial Engineering, 120, pp. 160178 (2018).

43. Mohagheghi, V., Mousavi, S.M., Vahdani, B., and Siadat, A. "A mathematical modeling approach for high and new technology-project portfolio selection under uncertain environments", Journal of Intelligent and Fuzzy Systems, 32, pp. 4069-4079 (2017).
44. Wang, L., Wang, H., Xu, Z., and Ren, Z. "The intervalvalued hesitant Pythagorean fuzzy set and its applications with extended TOPSIS and Choquet integralbased method", International Journal of Intelligent Systems, 34(6), pp. 1063-1085 (2019).

\section{Biographies}

Mahnaz Aghamohagheghi is currently a PhD student under the supervision of Professor Seyed Mehdi Hashemi at the Department of Mathematics and Computer Science at Amirkabir University of Technology and Professor Reza Tavakkoli-Moghaddam. She obtained her BSc and MSc in Computer Science from Amirkabir University of Technology in Tehran. Her research interests include fuzzy sets and systems, data mining, and decision-making problems.

Seyed Mehdi Hashemi is a Professor in the field of Applied Mathematics in Computer Science. He received his $\mathrm{PhD}$ degree from The University of Ottawa, Canada in 1996. He was a Professor and the Dean of Faculty of Mathematics and Computer Science at Amirkabir University of Technology where he taught several graduate and undergraduate courses, supervised $8 \mathrm{PhD}$ and more than 65 master students. Professor Hashemi's area of research includes graph theory and applications, algorithm and complexity, network and combinatorial optimization, operation research, and transportation systems, in which he has published more than 150 peer-reviewed journal and conference papers nationally and internationally. Professor Hashemi was involved in several industrial projects including designing and managing the enterprise application safety systems, designing integrated public transportation network for Tehran, and introducing the BRT system in collaboration with ITDP (Institute for Transportation and Development) and Iranian national ITS Architecture. Professor Hashemi has held various academic positions including Dean of Faculty of Mathematics and Computer Science, Chairman of ITSRI (Intelligent Transportation System Research Institute) at Amirkabir University of Technology, Chair of Iranian Operations Research Association, and member of Iranian Mathematical Association, Iranian Computer Association.

Reza Tavakkoli-Moghaddam is a Professor of Industrial Engineering at the College of Engineering, University of Tehran, Iran. He obtained his PhD, MSc, and BSc degrees in Industrial Engineering from the Swinburne University of Technology in Melbourne (1998), the University of Melbourne in Melbourne (1994), and the Iran University of Science and Technology in Tehran (1989), respectively. He serves as the Editor-in-Chief of the Journal of Industrial Engineering 
published by the University of Tehran and as the Editorial Board member of nine reputable academic journals. He is the recipient of the 2009 and 2011 Distinguished Researcher Awards and the 2010 and 2014 Distinguished Applied Research Awards at the University of Tehran, Iran. He has been selected as the National Iranian Distinguished Researcher in 2008 and 2010 by the MSRT (Ministry of Science,
Research, and Technology) in Iran. He has obtained an outstanding rank as the top 1group since 2014. He also received the Order of Academic Palms Award as a distinguished educator and scholar for the insignia of Chevalier dans l'Ordre des Palmes Academiques by the Ministry of National Education of France in 2019. He has published 5 books, 32 book chapters, and more than 1000 journal and conference papers. 